NASA/CR-2005-213851

\title{
Overview of Icing Physics Relevant to Scaling
}

David N. Anderson and Jen-Ching Tsao

Ohio Aerospace Institute, Brook Park, Ohio 
Since its founding, NASA has been dedicated to the advancement of aeronautics and space science. The NASA Scientific and Technical Information (STI) Program Office plays a key part in helping NASA maintain this important role.

The NASA STI Program Office is operated by Langley Research Center, the Lead Center for NASA's scientific and technical information. The NASA STI Program Office provides access to the NASA STI Database, the largest collection of aeronautical and space science STI in the world. The Program Office is also NASA's institutional mechanism for disseminating the results of its research and development activities. These results are published by NASA in the NASA STI Report Series, which includes the following report types:

- $\quad$ TECHNICAL PUBLICATION. Reports of completed research or a major significant phase of research that present the results of NASA programs and include extensive data or theoretical analysis. Includes compilations of significant scientific and technical data and information deemed to be of continuing reference value. NASA's counterpart of peerreviewed formal professional papers but has less stringent limitations on manuscript length and extent of graphic presentations.

- TECHNICAL MEMORANDUM. Scientific and technical findings that are preliminary or of specialized interest, e.g., quick release reports, working papers, and bibliographies that contain minimal annotation. Does not contain extensive analysis.

- CONTRACTOR REPORT. Scientific and technical findings by NASA-sponsored contractors and grantees.
- CONFERENCE PUBLICATION. Collected papers from scientific and technical conferences, symposia, seminars, or other meetings sponsored or cosponsored by NASA.

- SPECIAL PUBLICATION. Scientific, technical, or historical information from NASA programs, projects, and missions, often concerned with subjects having substantial public interest.

- TECHNICAL TRANSLATION. Englishlanguage translations of foreign scientific and technical material pertinent to NASA's mission.

Specialized services that complement the STI Program Office's diverse offerings include creating custom thesauri, building customized databases, organizing and publishing research results ... even providing videos.

For more information about the NASA STI Program Office, see the following:

- Access the NASA STI Program Home Page at http://www.sti.nasa.gov

- E-mail your question via the Internet to help@sti.nasa.gov

- Fax your question to the NASA Access Help Desk at 301-621-0134

- Telephone the NASA Access Help Desk at 301-621-0390

- Write to:

NASA Access Help Desk

NASA Center for AeroSpace Information 7121 Standard Drive

Hanover, MD 21076 
NASA/CR-2005-213851

\section{Overview of Icing Physics Relevant to Scaling}

David N. Anderson and Jen-Ching Tsao

Ohio Aerospace Institute, Brook Park, Ohio

Prepared for the

FAA In-Flight Icing/Ground De-Icing International Conference sponsored by the Society of Automotive Engineers

Chicago, Illinois, June 16-20, 2003

Prepared under Cooperative Agreement NCC3-884

National Aeronautics and

Space Administration

Glenn Research Center 


\section{Acknowledgments}

This work was supported by the NASA Aircraft Icing Research Project and by the FAA. The authors wish to thank Jim Riley of the FAA and Tom Bond of NASA for their support of this study as well as for valuable technical discussions and direction.

This report contains preliminary

findings, subject to revision as analysis proceeds.

Available from

NASA Center for Aerospace Information 7121 Standard Drive

Hanover, MD 21076
National Technical Information Service 5285 Port Royal Road Springfield, VA 22100 


\title{
Overview of Icing Physics Relevant to Scaling
}

\author{
David N. Anderson and Jen-Ching Tsao \\ Ohio Aerospace Institute \\ Brook Park, Ohio 44142
}

\begin{abstract}
An understanding of icing physics is required for the development of both scaling methods and ice-accretion prediction codes. This paper gives an overview of our present understanding of the important physical processes and the associated similarity parameters that determine the shape of Appendix $\mathrm{C}$ ice accretions.
\end{abstract}

For many years it has been recognized that ice accretion processes depend on flow effects over the model, on droplet trajectories, on the rate of water collection and time of exposure, and, for glaze ice, on a heat balance. For scaling applications, equations describing these events have been based on analyses at the stagnation line of the model and have resulted in the identification of several non-dimensional similarity parameters. The parameters include the modified inertia parameter of the water drop, the accumulation parameter and the freezing fraction. Other parameters dealing with the leadingedge heat balance have also been used for convenience. By equating scale expressions for these parameters to the values to be simulated a set of equations is produced which can be solved for the scale test conditions. Studies in the past few years have shown that at least one parameter in addition to those mentioned above is needed to describe surface-water effects, and some of the traditional parameters may not be as significant as once thought. Insight into the importance of each parameter, and the physical processes it represents, can be made by viewing whether ice shapes change, and the extent of the change, when each parameter is varied. Experimental evidence is presented to establish the importance of each of the traditionallyused parameters and to identify the possible form of a new similarity parameter to be used for scaling.

\section{INTRODUCTION}

Many components cannot be tested full size in an icing wind tunnel because of test-section blockage limitations. Furthermore, facilities that simulate natural icing can provide only limited ranges of air speed, cloud drop size, and liquid-water content. To accommodate sub-scale models or to extend the useful range of testing, it is often necessary to scale the model size or test parameters. The objectives of such scaling are to insure that the amount of ice relative to the model size, the shape of the ice accreted, dimensionless ice accretion limits, and the aerodynamic penalties due to the ice are the same as would have been obtained with the desired, or reference, model size or test conditions. It has always been assumed that for adequate scaling, characteristic features, such as glaze horns, need to be simulated in size, location, angle and shape, but how closely these characteristics need to match between scale and reference accretions has never been shown. For testing of iceprotection systems, the main objectives may be to match scale and reference non-dimensional accretion limits or water loading. In any case, it is important that scaling methods account for the appropriate physics.

Accurate scaling requires that similitude of geometry, flow field, drop trajectory, drop catch and heat balance be satisfied. However, these relationships may sometimes lead to conflicting values for one or more test parameters, making it necessary to apply simplifications to permit their use in practical scaling situations. A number of scaling methods have been derived from the basic set of similitude equations with emphasis on different similarity parameters and with varying assumptions applied. These methods provide guidance for the researcher in establishing proper scaling conditions.

For the testing of airfoils, when the desired model size cannot be accommodated in a test facility, an alternative approach to attempting to apply simplifications to the similitude equations is to use a hybrid scaling method. ${ }^{1,2,3}$ In this approach, a full-size leading-edge portion of a wing section is attached to a flapped section of reduced size. The flap is adjusted such that the flow field around the leading-edge region of the scale model is the same as that of the full-size airfoil. In the hybrid method, scale test temperature, airspeed, liquid-water content, median volume drop diameter and icing time are the desired full-size values. However, multiple models need to be fabricated for different flow conditions and angles of attack. The hybrid method will not be discussed further here.

In this paper, the most important similarity parameters will be reviewed, and results shown from icing tests performed to evaluate similarity parameters. The analyses and test results reported are for unprotected, unswept geometries for Appendix $\mathrm{C}$ conditions. Studies of the physics required to describe phenomena related to super-cooled large drop (SLD) icing is just beginning and will not be discussed. Nearly all of the experimental results presented were obtained in sea-level tunnels.

\section{SIMILITUDE ANALYSIS}

A scaling method is a procedure to determine the scaled test conditions necessary to produce an ice shape that 
simulates what the full-size model would accrete if exposed to the desired cloud conditions. To achieve this similarity in ice accretion, it is necessary for the scale test to simulate the geometry, the flowfield, the drop trajectories, the total water catch, the surface heat balance and the surface phenomena of the desired icing encounter. Because of the potential complexity, the analysis in this presentation is limited to the stagnation line. The assumption is made that if the scale accretion here is similar to the reference case, so will that which forms everywhere on the model.

\section{GEOMETRIC SIMILARITY}

The alternative to the hybrid scaling mentioned above is to make the reference and scaled models geometrically similar over the entire model. In this paper, the discussion will assume that scale and full-size, or reference, models have the same non-dimensional coordinates. As ice grows on the model, the shape must continue to be similar for both scale and reference to permit flowfield similarity. This basic requisite will be assumed for subsequent derivations of the other similitude requirements.

\section{FLOWFIELD SIMILARITY}

Similarity of the flowfield would suggest that the Reynolds and Mach numbers for the scaled test need to be matched to their respective reference values. The usual definitions for these parameters will be used:

$$
\begin{gathered}
R e=\frac{V d \rho_{a}}{\mu_{a}} \\
M=\frac{V}{\sqrt{V R_{a} T_{s t}}}
\end{gathered}
$$

In equation (1) the length scale $d$ represents either the diameter if the model is a cylinder or twice the leadingedge radius if the model is an airfoil. It was common practice in previous analyses to use the chord of the airfoil as the characteristic length; however, the main ice accretion occurs in the region near the leading edge. Therefore, in studying scaling similarity it seems reasonable to define similarity parameters in terms of a length representative of the leading-edge region. The convention of using $d$ to represent either cylinder diameter or twice the airfoil leading-edge radius will be used in the definition of all similarity parameters in this paper.

Icing occurs in the atmosphere only within the limited range of absolute temperature, $T_{s t}$, of 420 to $492^{\circ} \mathrm{R}$ (233 to $273 \mathrm{~K}$ ). Thus, because $\gamma$ and $R_{a}$ are constant properties of air, equating the Mach number for the scaled and reference cases requires that the velocities for the two be very nearly the same independent of scale model size. However, matching the Reynolds numbers requires the scale-to-reference velocity ratio to be approximately proportional to the reference-to-scale model size ratio. Clearly, then, Mach and Reynolds numbers cannot be simultaneously matched when the scale model is other than full size.
This problem has usually been solved by scaling analyses by disregarding both of these parameters. The rationale for this approach is that, for most icing conditions, the Mach number is relatively low and compressibility effects can be neglected. The Reynolds number has been ignored by arguing that ice accretions occur mostly at the leading edge of surfaces where the boundary layer is initially thin, and viscous effects are small. Farther downstream, as ice accretes it often causes the boundary layer to transition to turbulent flow, whose characteristics are nearly independent of Reynolds number.

In addition to Mach and Reynolds number considerations, simulation of the flowfield requires that the velocity, pressure and temperature distributions over the scale model must simulate those of the reference case. In subsequent derivations of equations, similarity of these distributions will be assumed.

\section{DROP TRAJECTORY SIMILARITY}

The mass of water reaching each part of the surface of each model must be similar. The drop trajectory determines if an individual drop will impinge on the surface of the model and, if so, where on the body. Thus, similarity of drop trajectory between scale and reference cases should ideally be satisfied. An analysis of the drop trajectories will be made in this section, and expressions will be derived which relate the scaled and reference values of some of the operating and test parameters of importance. The quantity of water available to reach the surface will be discussed in the section Water Catch Similarity.

Several simplifications are required to derive workable equations. It is assumed that the drop-size distribution in the cloud is the same for both scaled and reference cases and that the trajectories can be adequately represented by that of one representative drop diameter. Bragg, et $\mathrm{al}^{4}$ showed that for the typical distributions of drop size and relative velocity of icing experiments the drop motion and catch on a surface can be accurately represented by using the drop median volume diameter (MVD). Cloud drops involved in Appendix $C$ icing are in the range of 10 - to $50-\mu \mathrm{m}$ diameter; therefore, the effect of gravity is small and can be neglected. The drop momentum equation describing the motion of a single drop relative to the airstream has been given by both Bragg ${ }^{5}$ and Ruff. ${ }^{6}$

The modified inertia parameter, $K_{0}$, was developed by Langmuir and Blodgett ${ }^{7}$ by combining two dimensionless terms of the drop momentum equation:

$$
K_{0}=\frac{1}{8}+\frac{\lambda}{\lambda_{\text {Stokes }}}\left(K-\frac{1}{8}\right)
$$

where $K$ is the drop inertia parameter:

$$
K=\frac{V \delta^{2} \rho_{w}}{18 d \mu_{a}}
$$


and $\lambda / \lambda_{\text {Stokes }}$ is the range parameter

$$
\frac{\lambda}{\lambda_{\text {Stokes }}}=\frac{1}{R e_{\delta}} \int_{0}^{R e_{\delta}} \frac{24}{C_{D} R e_{\text {rel }}} \mathrm{d} R e_{\text {rel }}
$$

Here, $\lambda_{\text {Stokes }}$ is the range of the drop if it were released in still air at an initial velocity of $V$ with the drag given by Stokes' law, and $\lambda$ is the drop range with the actual drag. $R e_{r e l}$ is the Reynolds number based on the relative velocity between the drop and air, and $R e_{\delta}$ is the drop Reynolds number:

$$
R e_{\delta}=\frac{V \delta \rho_{a}}{\mu_{a}}
$$

The range parameter defined by equation (5) was tabulated by Langmuir and Blodgett as a function of $R e_{\delta}$. A fit to the Langmuir and Blodgett tabulation is

$$
\frac{\lambda}{\lambda_{\text {Stokes }}}=\left(\begin{array}{l}
0.8388+0.001483 R e_{\delta} \\
+0.1847 \sqrt{R e_{\delta}}
\end{array}\right)^{-1}
$$

To satisfy drop trajectory similarity it is only necessary that $K_{0, S}=K_{0, R}$. Equation (3) is only valid if $K$ is greater than 1/8. Langmuir and Blodgett noted that for $K \leq 1 / 8$ drop impingement would not occur.

Olsen $^{8}$ at NASA, Charpin and Fasso ${ }^{9}$ at ONERA and others used a simplified form of equation (3) along with an approximation to permit integration of equation (5). Bragg $^{5}$ also presented alternative approaches to that given here. These simplifications permitted solving for the scale drop size directly in terms of reference conditions and other scale parameters. When equations are programmed into computers to solve for scaling conditions, however, these simplifications are unnecessary, and scaling studies at NASA Glenn for the past 10 years have matched scale and reference $K_{0}$ to solve for scale drop size.

The catch efficiency, $\beta$, varies over the model surface with a value $\beta_{0}$ at the stagnation line. Langmuir and Blodgett $^{7}$ published tables of the stagnation-point catch efficiency as a function of the parameters, $K$ and $K_{0}$ for cylinders. They showed that fairly accurate values of $\beta_{0}$ could be calculated from the following equation for $K \leq$ 7.5:

$$
\beta_{0}=\frac{1.40\left(K_{0}-1 / 8\right)^{0.84}}{1+1.40\left(K_{0}-1 / 8\right)^{0.84}}
$$

To test the validity of this expression for a range of icing conditions, $\beta_{0}$ calculated from equation (8) was compared with values from the LEWICE ice accretion code ${ }^{10}$ at both 0 and $10^{\circ} \mathrm{AOA}$. The results are given in figure 1 , and it can be seen that there is close agreement between LEWICE and equation (8). For the NACA 0012 airfoil used for these computations $\beta_{0}$ varies little from 0 to $10^{\circ} \mathrm{AOA}$. If the scale model is mounted at the identical $\mathrm{AOA}$ as the reference, matching of $K_{0}$ will still produce the correct drop trajectories for the scale test although there will be a small error in $\beta_{0}$ if equation (8) is used. The conditions considered in figure 1 provide a range of inertia parameter, $K$, of 0.72 to 202 , suggesting that Langmuir and Blodgett's upper limit of $K=7.5$ for equation (8) is very conservative.

Equation (8) shows that to match $\beta_{0}$ between scale and reference values, it is only necessary to match $K_{0}$. The initial capture efficiency is assumed to be that at the stagnation line of a clean surface. It can be argued for scaling, however, that aft of the stagnation line, because scale and reference models are geometrically similar and the flowfields are also similar, the collection efficiencies must vary in the same way for both models. This agreement of scale and reference collection efficiencies is shown in figure 2, which gives LEWICE predictions for two NACA 0012 airfoils of different sizes. The conditions for the smaller model were scaled from those of the larger such that the stagnation $K_{0}$ (and therefore $\beta_{0}$ ) for the two matched. The two curves are indistinguishable over the range for which accretion occurs; to help identify the curve for the reference case the area under that plot has been shaded. Figure 2 confirms that it is only necessary to match the stagnation $K_{0}$ to properly scale drop trajectories that impinge everywhere on the model. It is assumed that as ice accretes, because the geometry changes in the same way for both scale and reference models, the time-varying collection efficiency will continue to match everywhere.

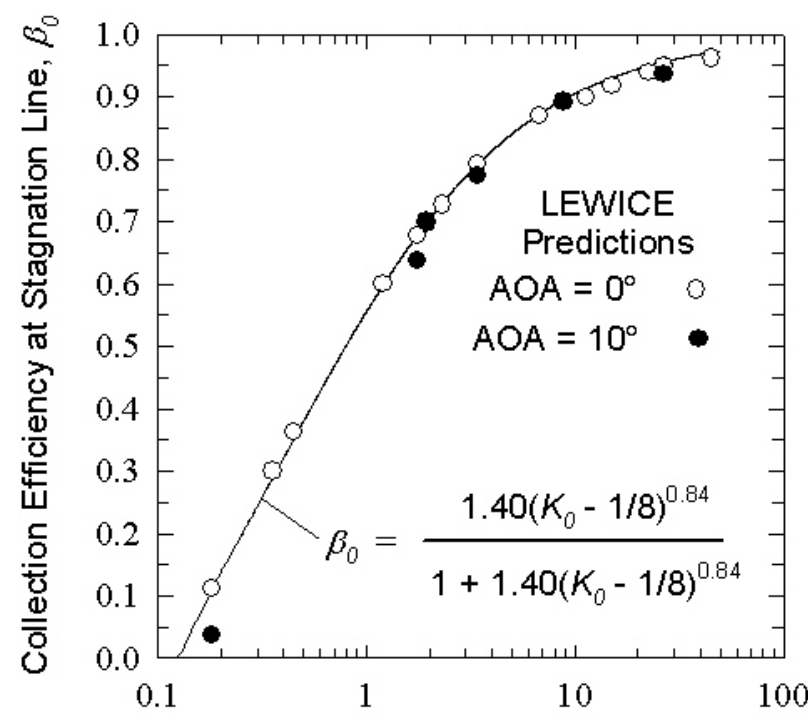

$$
\text { Modified Inertia Parameter, } K_{0}
$$

Figure 1. Stagnation Collection Efficiency for NACA 0012 Airfoils at 0 and $10^{\circ} \mathrm{AOA}$. $t_{s t},-30$ to $25^{\circ} \mathrm{F} ; p_{s t}, 14 \mathrm{psia}$; , 100 and $400 \mathrm{mph} ; \delta, 10$ to $100 \mu \mathrm{m} ; L W C, 1 \mathrm{~g} / \mathrm{m}^{3}$. 
Derivation of the equations for trajectory similitude assumed that a single drop diameter, the median volume diameter, adequately represents the cloud and its trajectory. At any instant during icing the size of a drop impacting a particular location on the model surface cannot be predicted. Thus, in glaze ice conditions in particular, features of the ice shape tend to be subject to a certain randomness; therefore, icing encounters repeated with the same model and identical test conditions cannot be expected to produce identical ice shapes. Fortunately, however, noticeable differences on the macroscopic scale are usually minor.

\section{Effect of $\beta_{0}$ on Ice Shape}

In 1998 Chen ${ }^{11}$ performed several icing tests to compare shapes with drop MVD's of 20, 36 and $55 \mu \mathrm{m}$. The tests were made in the IRT using a 24-in-chord GLC 305 airfoil model with constant $t_{s t}, V$ and accretion time. LWC was adjusted to maintain constant freezing fraction, $n_{0}$, for each set of tests. The freezing fraction was defined by Messinger ${ }^{12}$ as the ratio of the mass of water that freezes at a given location on the surface to the total mass of liquid water that reaches the surface at that location. The freezing fraction will be discussed in more detail in the section on energy balance similarity. In Chen's study, because velocity and model size were fixed, $\beta_{0}$ varied with MVD. The quantity of ice collected is determined by the product $\beta_{0} A_{c}$, and this value was maintained within about $10 \%$. The accumulation parameter, $A_{c}$, will be discussed in the next section. Results for drop sizes of 55 and $20 \mu \mathrm{m}$ are given in

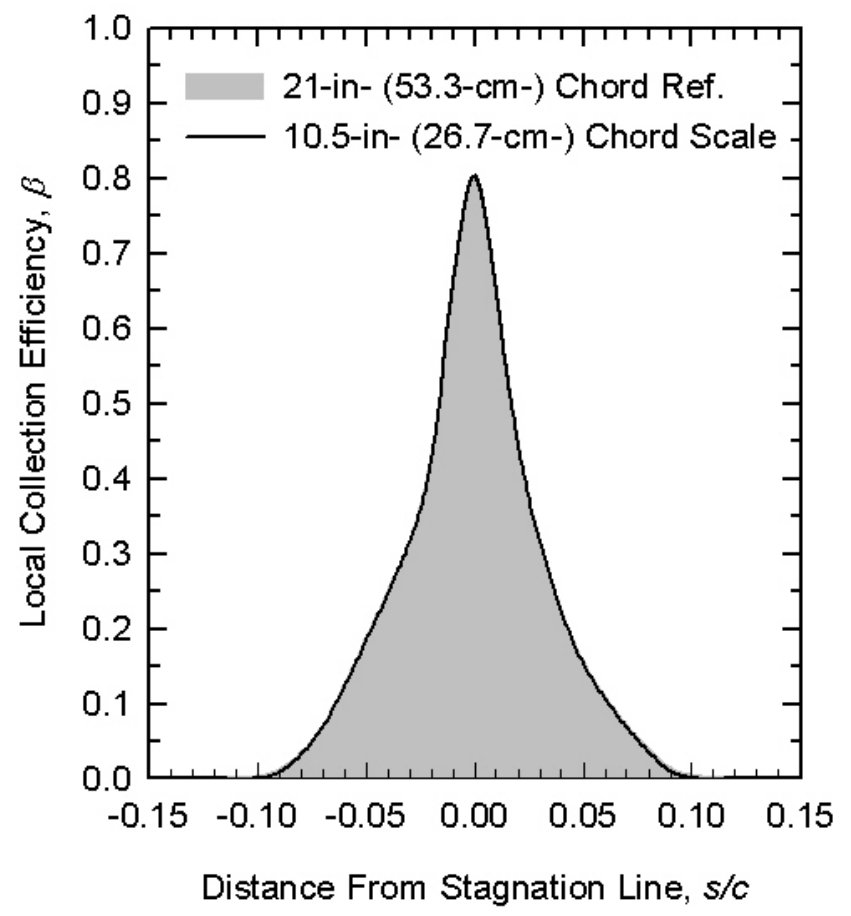

Figure 2. LEWICE-Predicted Reference and Scale Collection Efficiencies. NACA 0012 Airfoils. Reference Conditions: $C_{R}, 21$ in $(53.3 \mathrm{~cm}) ; V_{R}, 150 \mathrm{mph}(67 \mathrm{~m} / \mathrm{s})$; $\delta_{R}, 30 \mu \mathrm{m}$. Scale Conditions: $c_{S}, 10.5$ in $(26.7 \mathrm{~cm}) ; V_{S}$, $262.5 \mathrm{mph}(117 \mathrm{~m} / \mathrm{s}) ; \delta_{S}, 15.6 \mu \mathrm{m}$. figure 3. Although $\beta_{0}$ changed from about 92 to $74 \%$, this reduction appeared to have no effect on the main ice shape. Undoubtedly, the icing limit would have changed with drop size (that is, with $\beta_{0}$ ), but this feature was not measured.

The implications of these results for scaling are significant. Within the FAA FAR-25 Appendix C envelope, the main ice shape appears to be virtually independent of drop size. Thus, if calculated conditions for a scale model test involve drop sizes outside the available range for a particular test facility, it may be possible to substitute a different $\delta$, providing the key parameters $\beta_{0} A_{c}$ and $n_{0}$ are maintained at the reference values. If $\beta_{0}$ is not matched, however, trajectories impinging aft of the main ice shape will not be similar for scale and reference. Therefore, when impingement limits are needed they must be found from tests whose conditions provide a match of $\beta_{0}$. Further testing is needed to define better the effect of drop size on ice shape.

\section{WATER CATCH SIMILARITY}

The total amount of water reaching the surface depends on local collection efficiency, rate of water flow towards the model and accretion time. Assuming that all the impinging water freezes on impact (i.e., $n=1$ ), that $\beta$ is independent of the changing ice shape with time and that $\rho_{i}$ does not significantly vary as ice is accreted, the ice thickness, $\Delta$ would be given by:

$$
\Delta=\frac{L W C V \beta T}{\rho_{i}}
$$

At the stagnation line the ice thickness for glaze ice $\left(n_{0}<\right.$ 1) normalized by model size is given by

$$
\frac{\Delta_{0}}{d}=\beta_{0} A_{c} n_{0}
$$




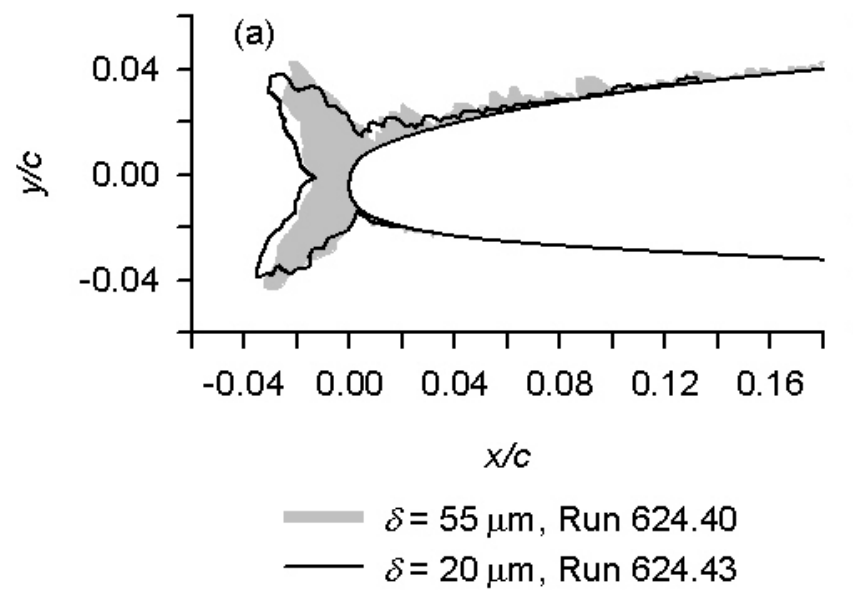

(a) $n=0.28$

\begin{tabular}{|c|c|c|c|c|c|c|c|c|c|c|c|c|c|c|}
\hline un & $\begin{array}{l}c, \\
\text { in }\end{array}$ & $\begin{array}{l}t_{s t}, \\
{ }^{\circ} \mathrm{F}\end{array}$ & $\begin{array}{c}V, \\
\mathrm{mph}\end{array}$ & $\begin{array}{c}\delta, \\
\mu \mathrm{m}\end{array}$ & $\begin{array}{l}L W C, \\
\mathrm{~g} / \mathrm{m}^{3}\end{array}$ & $\underset{\min }{\tau}$ & $\begin{array}{l}\beta_{0} \\
\%\end{array}$ & $A_{c}$ & $n_{0}$ & $b$ & $\begin{array}{l}\phi, \\
{ }^{\circ} \mathrm{F}\end{array}$ & $\begin{array}{l}\theta, \\
{ }^{\circ} \mathrm{F}\end{array}$ & $\begin{array}{l}R e \\
10^{4}\end{array}$ & $\begin{array}{r}W e_{L}, \\
10^{6}\end{array}$ \\
\hline 4 & 24 & 14 & 200 & 55 & 1.16 & 6.1 & 91.6 & 2.53 & 0.28 & 0.84 & 16.1 & 20.3 & 10.9 & 2.0 \\
\hline & 24 & 14 & 198 & 20 & 1.31 & 6.1 & 73.9 & 2.83 & 0.30 & 0.76 & 15.9 & 20.2 & 10.8 & 1.98 \\
\hline & 24 & 2 & 200 & 55 & 1.16 & 6.1 & 91.7 & 2.53 & 0.51 & 0.84 & 28.6 & 36.8 & 11.4 & 2.0 \\
\hline & 24 & 2 & 200 & 20 & 1.30 & 6.1 & 74.0 & 2.83 & 0.54 & 0.76 & 28.5 & 36.7 & 11.4 & 2.0 \\
\hline
\end{tabular}

Figure 3. Effect of Drop MVD on Ice Shape. GLC 305 Airfoil. Ice-Shape Data from Tests by Chen. ${ }^{11}$

where the accumulation parameter, $A_{c}$, is defined as

$$
A_{c}=\frac{L W C V_{T}}{\rho_{i} d}
$$

One goal of properly scaling the ice accretion is that the local normalized thickness of ice should be the same for the scaled and reference cases. If $\beta_{0, S} A_{c, S} n_{0, S}=$ $\beta_{0, R} A_{c, R} n_{0, R}$ the thickness of the scale ice at stagnation, relative to the model size, will match that of the reference. We have already seen that to insure trajectory similarity it's necessary to match scale and reference values of $K_{0}$, and from equation (8) if the $K_{0}$ match, so do the $\beta_{0}$. In the next section, it will be shown that $n_{0}$ must also match. Therefore, water catch similarity (icethickness similarity) is typically satisfied by requiring that $A_{c, S}=A_{c, R}$. With the assumption that $\rho_{i}$ is the same for scaled and reference cases, the ratio of scale-toreference accretion time from equation (11) is:

$$
\frac{T_{S}}{T_{R}}=\left(\frac{d_{S}}{d_{R}}\right)\left(\frac{V_{R}}{V_{S}}\right)\left(\frac{L W C_{R}}{L W C_{S}}\right)
$$

For airfoils, of course, the ratio $\left(d_{S} / d_{R}\right)=\left(c_{S} / c_{R}\right)$. If it is not possible to find scaled conditions that permitted a match of $K_{0}$, then scale and reference $\beta_{0} A_{c}$ must match.

\section{ENERGY BALANCE SIMILARITY}

If all the water impinging on a surface were to freeze on impact, $K_{o, S}=K_{0, R}$ and $A_{c, S}=A_{c, R}$ would be sufficient to satisfy scaling. This situation applies to rime ice formation. However, the fraction of water that freezes, $n$, is (b)

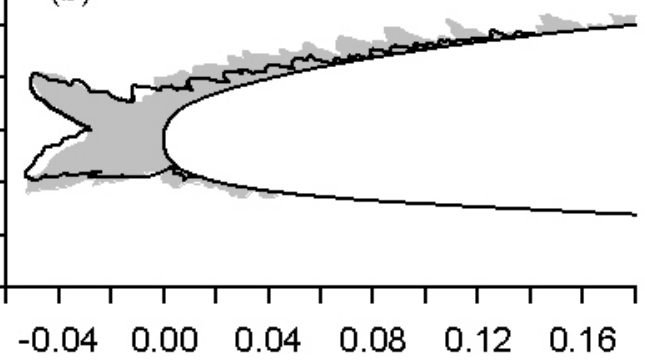

$x / c$

$\delta=55 \mu \mathrm{m}$, Run 924.40

$-\delta=20 \mu \mathrm{m}$, Run 924.43

(b) $n=0.52$

not always unity, and energy-balance similarity must be satisfied for glaze ice accretions.

The rate at which water freezes on a surface depends on the local heat balance. Tribus, et $\mathrm{al}^{13}$ studied heat transfer for a heated cylinder in icing conditions. Their analysis is useful for thermal deicing or anti-icing systems. Messinger ${ }^{12}$ later performed the classical energybalance analysis for freezing at an unheated surface. Messinger's work was further developed by Ruff. ${ }^{6}$ The similitude relations to be presented here are for an unheated surface and are based primarily on the Messinger and Ruff analyses. The energy terms for this case, expressed per unit area, are:

(1) Energy lost from the surface by convection through the boundary layer: $q_{c}=h_{c}\left(t_{s}-t_{b l}\right)$.

(2) Energy lost from the surface due to evaporation of water: $q_{e}=\dot{m}_{e} \Lambda_{v}$.

(3) Energy lost from the surface to raise the temperature of the impinging liquid to the freezing point: $q_{w}=\dot{m} c_{p, w s}\left(t_{s}-t_{s t}\right)$.

(4) Energy gained by the surface due to release of latent heat of fusion from the freezing water: $q_{f}=\dot{m} n_{0} \Lambda_{f}$.

(5) Energy gained by the surface from the kinetic energy of the water drops striking the surface: $q_{k}=\dot{m}\left(\frac{1}{2} V^{2}\right)$.

When the surface temperature reaches steady state, the net heat transfer is zero. Thus, the energy-balance equation is

$$
q_{c}+q_{e}+q_{w}=q_{f}+q_{k}
$$

As with the drop trajectory analysis, the energy balance will be evaluated only at the stagnation line for scaling. It is assumed that if scale and reference conditions are matched there, they will also match everywhere. In ad- 
dition, the energy balance on the clean airfoil (before ice begins to accrete) is used. If the clean heat balance matches for two models and similarity is maintained in all the physical phenomena that affect the shape of the accreting ice, the balance, although changing with time, will be the same for the two models as ice develops.

Equation (13) is adequate for a scaling analysis. Other terms needed for a complete analysis include the sensible heat gained as ice cools from the freezing temperature to the surface temperature, sublimation, radiation, surface water in-flow, surface water run back and conduction into the model surface. For glaze ice there is no sensible heat from cooling the ice, because the surface temperature, $t_{s}$, is equal to the freezing temperature, $t_{f}$. For this paper, the energy balance will be written for glaze ice only, so this contribution is neglected. The sublimation is small compared with the evaporation of liquid, and for unheated surfaces radiation is also insignificant. The analysis is limited to the stagnation line of the model where water arrives only by impingement; therefore, heat carried into the control volume by water flowing from a neighboring location can be omitted. Heat carried away by water flowing out of the control volume to a neighboring location has also been neglected on the basis that temperature differences between a stagnation control volume and a neighboring one will be negligible. For thermal ice protection this term may need to be considered, but for this paper iceprotection systems will not be discussed. Finally, conduction effects can be neglected for icing times greater than a few seconds because the ice quickly produces an insulating layer over the model surface.

The film coefficient in term (1), $h_{c}$, varies with position on the model. Kreith ${ }^{14}$ gives the following relationship for $\mathrm{Nu}$ for the stagnation line of a cylinder:

$$
N u=1.14 \operatorname{Pr}^{0.4} \operatorname{Re}^{0.5}
$$

where

$$
N u=\frac{h_{c} d}{k_{a}}
$$

The air properties for $\mathrm{Nu}, \mathrm{Pr}$, and $\mathrm{Re}$ in equation (14) are evaluated at the film temperature, which is taken as the average of the free-stream and surface temperatures,

$$
t_{\text {film }}=\frac{1}{2}\left(t_{s}+t_{s t}\right)
$$

For glaze ice the surface temperature is $0^{\circ} \mathrm{C}$, and over a free-stream temperature range of -40 to $0^{\circ} \mathrm{C}$, the range of interest to icing, the Prevaluated at film temperatures varies only from .708 to .705 ; thus, $1.14 \mathrm{Pr}^{4}$ has a nearly constant value of .992 . Then

$$
N u=0.992 R e^{0.5}
$$

Ruff $^{6}$ used equation (14) to find the convective heat transfer coefficient for both cylinders and airfoils and this expression is also used in NASA scaling research. Its validity was confirmed by Poinsatte ${ }^{15}$ and Van Fossen. ${ }^{16}$ At the stagnation line of a clean, smooth NACA 0012 airfoil at $0^{\circ} \mathrm{AOA}$ in the IRT, Poinsatte found

$$
N u=1.100 R e^{0.472}
$$

The coefficients in Poinsatte's study had an uncertainty of about $\pm 5 \%$. Poinsatte's original results used $\mathrm{Nu}$ and $R e$ based on chord, but in equation (18) they have been converted to a $d$-basis for consistency with the practice in this paper. For the NACA 0012 airfoil, $d=.0316 c$. The Poinsatte 0012 data correlations of equation (18) are within $10 \%$ of the Kreith cylinder coefficients and exponents of equation (17). Van Fossen's clean, smooth cylinder tests for IRT turbulence levels produced a coefficient about $25 \%$ higher than Kreith's and a $R e$ exponent within $5 \%$. For scale testing in an icing tunnel with turbulence levels similar to those of the IRT, it is recommended that Kreith's expression for $\mathrm{Nu}$ be used because of its consistency with these experimental results for both cylinder and airfoil models.

At the stagnation point, $t_{b l}=t_{s t}+V^{2} / 2 c_{p, a}$. Thus, heat balance term (1) is $q_{c}=h_{c}\left(t_{s}-t_{s t}-V^{2} / 2 c_{p, a}\right)$.

In heat balance term (2), the mass of water which evaporates, $\dot{m}_{e}$, is

$$
\dot{m}_{e}=h_{G} \frac{\left(p_{w w}-p_{w}\right)}{p_{s t}}
$$

The driving force for evaporation in equation (19) is the difference between the partial pressure of vapor at the surface, $p_{w w}$, and that in the atmosphere, $p_{w}$. The form given here neglects compressibility effects. The vapor pressure over water at the surface is assumed the saturation pressure at the surface temperature. A curve fit for the saturation pressure of vapor over water was given by Pruppacher and $\mathrm{Klett}^{17}$ for the range of $-50^{\circ} \mathrm{C}$ to $50^{\circ} \mathrm{C}$. Their expression is a convenient way to evaluate $p_{w w}$ and $p_{w}$. Ruff ${ }^{6}$ derived a compressible form of the evaporation driving force. Equation (19) in compressible form is

$$
\dot{m}_{e}=h_{G}\left(\frac{\frac{p_{w w}}{T_{s t}}-\frac{p_{\text {tot }}}{T_{\text {tot }}} \frac{p_{w}}{p_{s t}}}{\frac{1}{0.622} \frac{p_{\text {tot }}}{T_{\text {tot }}}-\frac{p_{w w}}{T_{s t}}}\right)
$$

Compressibility effects are typically negligible for icing conditions. In equations (19) and (20) $h_{G}$ is the gasphase convective mass transfer coefficient. It is analogous to the convective heat-transfer coefficient. The theoretical relationship between $h_{G}$ and $h_{c}$ can be expressed in terms of the Schmidt and Prandtl numbers as (see, for example, ref. 14):

$$
h_{G}=\frac{h_{c}}{c_{p, a}}\left(\frac{P r}{S c}\right)^{0.67}
$$


In equation (21) Pr and Sc are those for air, with properties evaluated at the film temperature, $t_{\text {film }}$, from equation (16):

$$
\begin{aligned}
& \operatorname{Pr}=\frac{c_{p, a} \mu_{a}}{k_{a}} \\
& S c=\frac{\mu_{a}}{\rho_{a} D_{v}}
\end{aligned}
$$

With these definitions, the energy balance of equation (13) written for the stagnation line is

$$
\begin{aligned}
& h_{c}\left(t_{s}-t_{s t}-\frac{V^{2}}{2 c_{p, a}}\right)+h_{G}\left(\frac{\frac{p_{w w}}{T_{s t}}-\frac{p_{t o t}}{T_{t o t}} \frac{p_{w}}{p_{s t}}}{\frac{1}{0.622} \frac{p_{t o t}}{T_{t o t}}-\frac{p_{w w}}{T_{s t}}}\right) \Lambda_{v} \\
& +\dot{m} c_{p, w s}\left(t_{f}-t_{s t}\right)=\dot{m} n_{0} \Lambda_{f}+\dot{m} \frac{V^{2}}{2}
\end{aligned}
$$

Tribus $^{13}$ introduced the dimensionless parameter $b$ known as the relative heat factor:

$$
b=\frac{\dot{m} c_{p, w s}}{h_{c}}=\frac{L W C V \beta_{o} c_{p, w s}}{h_{c}}
$$

It relates the total heat capacity of the impinging water to the ability of the surface to convect heat. Note that $b$ is evaluated at the stagnation line because $\beta_{0}$ is the local stagnation catch efficiency, found from equation (8).

Two other parameters often used for convenience are $\phi$ and $\theta$ which have dimensions of temperature and relate to the drop energy transfer and air energy transfer, respectively:

$$
\varphi=t_{f}-t_{s t}-\frac{V^{2}}{2 c_{p, w s}}
$$

and

$$
\theta=\left(t_{s}-t_{s t}-\frac{V^{2}}{2 c_{p, a}}\right)+\frac{h_{G}}{h_{c}}\left(\frac{\frac{p_{w w}}{T_{s t}}-\frac{p_{t o t}}{T_{t o t}} \frac{p_{w}}{p_{s t}}}{\frac{1}{0.622} \frac{p_{t o t}}{T_{\text {tot }}}-\frac{p_{w w}}{T_{s t}}}\right) \Lambda_{v}
$$

This form of $\theta$ includes compressibility effects.

When the glaze-ice energy balance, equation (24), is rewritten in terms of the parameters $b, \phi$ and $\theta$, the terms can be arranged to give an expression for the freezing fraction:

$$
n_{0}=\left(\frac{c_{p, w s}}{\Lambda_{f}}\right)\left(\varphi+\frac{\theta}{b}\right)
$$

A freezing fraction of 0 implies that no freezing occurs, while a freezing fraction of 1 indicate that water freezes on impact. The latter situation produces rime ice. Experimental evidence to validate equation (28) will be presented below.
The Ruff scaling method finds scale $L W C$ by setting $n_{0, S}$ $=n_{0, R}$. By using $n_{0}$ as the heat-balance parameter to match for scale studies, the implicit assumption is that if $n_{0, S}=n_{0, R}$ then $n$ will also match everywhere. Furthermore, strictly speaking, equation (28) applies only to a clean airfoil. As ice accretes, the stagnation freezing fraction can be expected to change because the geometry is continually changing. Thus, for scaling it is necessary to assume additionally that if $n_{0}$ varies with time, it does so in such a way that if $n_{O, S}=n_{O, R}$ at the initiation of spray, freezing fractions will continue to match during the course of ice accretion. This is not an unreasonable assumption because the goal of scaling is to maintain similar ice shapes for scale and reference. If this goal is met the time variation of $n_{0, S}$ and $n_{0, R}$ should be the same.

Kind and coauthors ${ }^{18,19}$ formulated the energy equation to give a freezing-fraction expression valid for any position on the surface, rather than just the stagnation line. Two parameters were used with the first incorporating terms independent of location and the second varying with distance from the stagnation line. They gave LEWICE predictions showing that when the stagnation $n_{0}$ matched, reference and scale local freezing fractions also matched from the stagnation line back to about $\mathrm{s} / \mathrm{c}$ $= \pm 0.02$. This is the region of greatest interest to icing because most of the main ice shape is accreted there. However, it's important to keep in mind that LEWICE predictions of freezing fraction have not been validated experimentally the way collection efficiencies have, and therefore there is less confidence in the value of $n$ from LEWICE.

Kind and associates also concluded that scale ice shapes simulated reference shapes best when the scale and reference static temperatures matched. However, all of their observations were made with scale velocities of $100 \mathrm{~m} / \mathrm{s}(224 \mathrm{mph})$ or less. For such air speeds the velocity term is never more than approximately $2^{\circ} \mathrm{F}$, and equation (26) shows that if scale and reference $\phi$ match the temperatures will also nearly match. It would appear that the matching of $\phi$ is more general than simply matching $t_{s t}$. Matching of $\phi$ to find scale static temperature is a requirement of the Ruff ${ }^{6}$ scaling method.

For rime ice, because water freezes on impact, the energy balance does not affect the ice shape. Consequently, no energy balance needs to be considered when scaling rime.

\section{Effect of Temperature and $L W C$}

The strong effect of the freezing fraction on ice shape has been demonstrated by numerous studies with both cylinders and NACA 0012 airfoils ${ }^{20,21}$. A few examples of the effect of changing either temperature or $L W C$, both of which have a significant influence on $n_{0}$, will be given.

Ice shape changes with incremental changes in temperature are shown in figure 4 . These unpublished tests 
were performed in the NASA Glenn IRT using 21-in(53.3-cm-) chord NACA 0012 airfoil models. In each portion of the figure, two ice shapes are compared for which the temperature was changed with all other test parameters held constant. For all tests $K_{0}$ was constant to give a fixed value of $\beta_{0}$ of $0.85, A_{c}$ was 1.88 and $b$ was 0.58 . For each $5^{\circ} \mathrm{F}$ decrease in temperature, the parameter $\phi$ increased approximately $5^{\circ} \mathrm{F}$ and $\theta$ increased about $7^{\circ} \mathrm{F}$. The freezing fraction also increased as indicated in the figure with decreasing temperature. The ice shape for the warmer-temperature of each pair is shown shaded while the colder of the two is represented with a
With each incremental decrease in temperature (and consequent increase in $n_{0}$ ) the horns moved forward and the leading-edge ice thickness increased (consistent with eq. (10)). The exception to this general trend occurred when $n_{0}$ was increased from 0.52 to 0.61 (fig. 4 (c)). Although the ice thickness increased, there was no significant change in horn angle for this range of freezing fraction.

With constant test parameters $c, V, \delta, L W C$, and $\tau$ and constant similarity parameters $K_{0}$ (or $\beta_{0}$ ), $A_{c}$ and $b$ for the range of temperatures tested in figure 4 , it must be reasoned that only the varying parameters $n_{0}, \phi$ or $\theta$ can be responsible

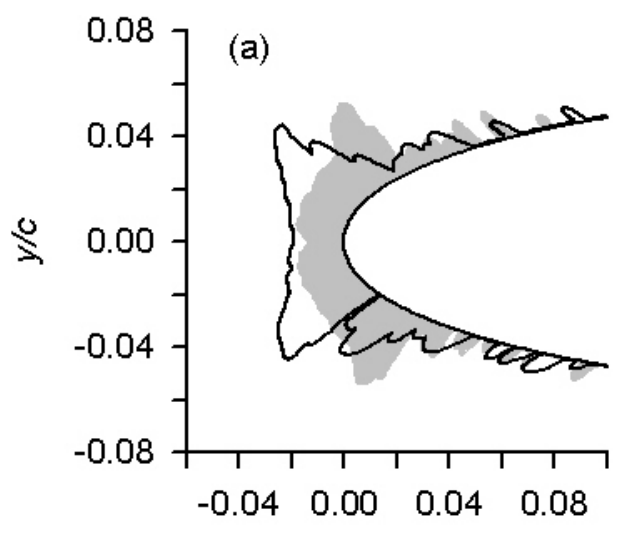

$x / c$

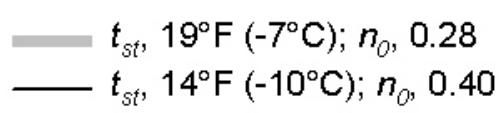

(a) Temperatures of 19 and $14^{\circ} \mathrm{F}$ $\left(-7\right.$ and $\left.-10^{\circ} \mathrm{C}\right)$.

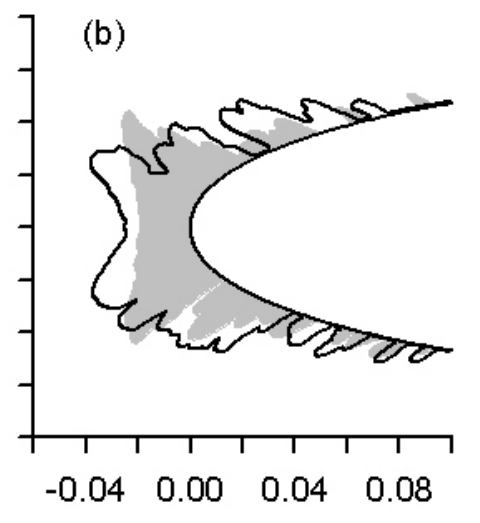

$X / C$

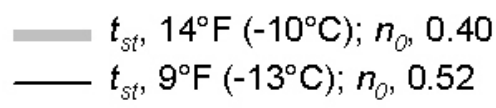

(b) Temperatures of 14 and $9^{\circ} \mathrm{F}\left(-10\right.$ and $\left.-13^{\circ} \mathrm{C}\right)$.

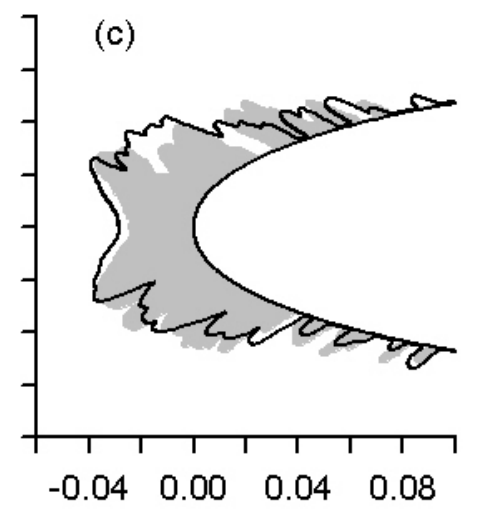

$x / c$ for the

changes

observed in

ice shape.

Further evi-

dence will

next be

shown to

isolate

which of

these three

has the

greatest

impact on

shape.

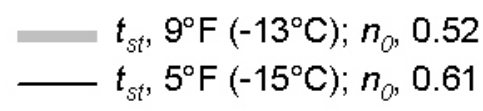

(c) Temperatures of 9 and $5^{\circ} \mathrm{F}$ $\left(-13\right.$ and $\left.-15^{\circ} \mathrm{C}\right)$.
Figure 5 presents results of a series of tests re-

solid line.

ported in reference 20. For these tests, the parameters $c, V$, and $\delta$ were maintained constant; consequently, $K_{0}$

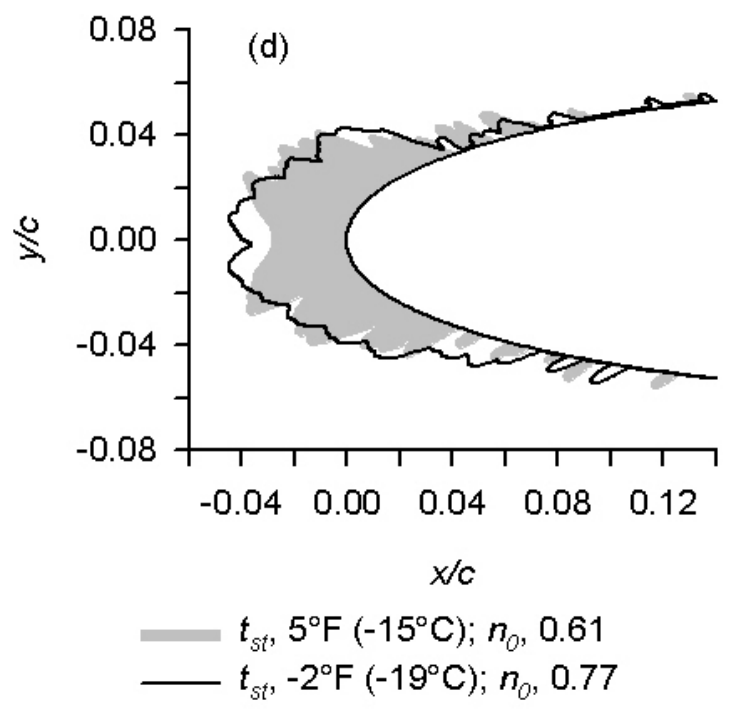

(d) Temperatures of 5 and $-2^{\circ} \mathrm{F}$ $\left(-15\right.$ and $\left.-19^{\circ} \mathrm{C}\right)$ (e)

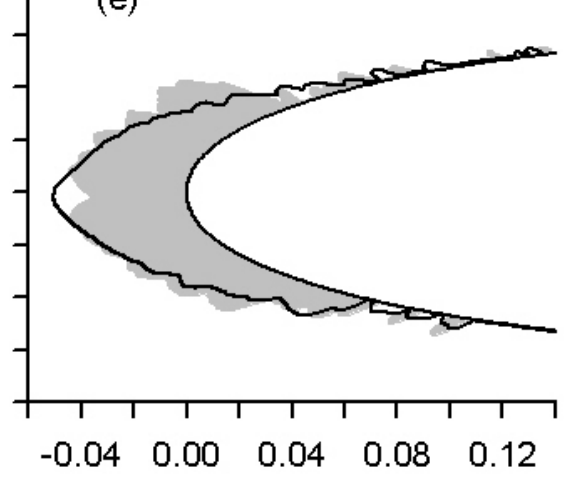

$x / c$

$t_{s t},-2^{\circ} \mathrm{F}\left(-19^{\circ} \mathrm{C}\right) ; n_{0}, 0.77$

$-t_{s t},-16^{\circ} \mathrm{F}\left(-27^{\circ} \mathrm{C}\right) ; n_{0}, 1.00$

(e) Temperatures of -2 and $-16^{\circ} \mathrm{F}$ $\left(-19\right.$ and $\left.-27^{\circ} \mathrm{C}\right)$.

Figure 4. Effect of Static Temperature on Ice Shape. Unpublished NASA data by Anderson. NACA 0012 Airfoil, c, 21 in $(53.3 \mathrm{~cm}) ; V, 150 \mathrm{mph}(67 \mathrm{~m} / \mathrm{s}) ; \delta, 38 \mu \mathrm{m}$; $L W C, 1.0 \mathrm{~g} / \mathrm{m}^{3} ; \tau, 7.3 \mathrm{~min} ; \beta_{0}, 0.85 ; A_{c}, 1.88 ; b, 0.58$.

(or $\beta_{0}$ ) was constant, while $L W C$ varied. The icing time was adjusted to keep $A_{c}$ the same for both tests in each portion of the figure. Again, the model was a 21-in- (53.3-cm-) chord NACA 0012 tested in the NASA Glenn IRT. The shaded ice shape in each portion of the figure was recorded for an $L W C$ of $1.4 \mathrm{~g} / \mathrm{m}^{3}$, while the shape indicated by a solid line was obtained with an $L W C$ of $0.8 \mathrm{~g} / \mathrm{m}^{3}$.

For the two ice shapes shown in figure 5 (a) $t_{s t}$ was the same; therefore, $n_{0}$ increased with decreasing $\angle W C$. As the $\angle W C$ was decreased from 1.4 to $0.8 \mathrm{~g} / \mathrm{m}^{3}$ the horns on the main ice shape moved forward and the leadingedge thickness increased, similar to the effect of decreasing the static temperature shown in figure 4 . For both shapes $\phi$ was 
$20^{\circ} \mathrm{F}$ and $\theta$ was $28^{\circ} \mathrm{F}$. The relative heat factor was 0.77 for the higher $L W C$ test and 0.44 for the lower LWC. Therefore, keeping $\phi$ and $\theta$ constant failed to keep the ice shapes the same when freezing fraction and $b$ varied.

Figure 5 (b) gives results of tests in which the temperature was varied to maintain a constant freezing fraction as $L W C$ changed. These two ice shapes agreed. The value of $\phi$ changed from 27 to $18^{\circ} \mathrm{F}$ and $\theta$ decreased from 36 to $25^{\circ} \mathrm{F}$ with the increase in temperature from 4 to $13^{\circ} \mathrm{F}$. $b$ decreased from 0.77 to 0.44 with the reduction in $L W C$ from 1.4 to $0.8 \mathrm{~g} / \mathrm{m}^{3}$. The ability to match shapes by matching $n_{0}$, although the temperature and liquid water content differed, shows that $t_{s t}$ and $L W C$ do not have an effect on ice shape independent of $n_{0}$. Furthermore, as long as freezing fraction matches, it is not necessary to match the energy parameters $\phi, \theta$ or $b$.

The results of the three test series shown in figures 4 and 5 demonstrate the very strong effect of freezing fraction on ice shape. The energy parameters $b, \phi$ and $\theta$ are related to $n_{0}$ through equation (28) but appear to have little or no independent effect on ice shape. These results demonstrate that either $L W C$ or $t_{s t}$ can be scaled from one value to another simply by adjusting $t_{s t}$ or $L W C$, respectively, to keep the freezing fraction constant. This approach to scaling test conditions is known as the OIsen method. ${ }^{8}$

\section{Validation of the Freezing Fraction Expression}

Using equation (10) it is possible to calculate an experimental freezing fraction from the leading-edge thickness once the $\beta_{0}$ and $A_{c}$ are determined from test conditions. This was done by Anderson and $\mathrm{Tsao}^{22}$ and the results compared with the analytical freezing fraction formulation presented in equation (28). To distinguish between the experimentally-derived and analytical freezing fractions, $n_{e}$ and $n_{a}$ will be used, respectively.
The Anderson and Tsao study was based on icing tests in the IRT using NACA 0012 models with chords of 10.5 $-31.5 \mathrm{in}(26.7-80 \mathrm{~cm})$, velocities of $106-257 \mathrm{mph}$ (48 $-115 \mathrm{~m} / \mathrm{s}$ ) and drop MVD's of $21.5-46 \mu \mathrm{m}$. The experimentally-derived freezing fractions are plotted against the analytical values in figure 6 . Open symbols were measured from ice tracings taken at mid-span $(\mathrm{CL})$ and the solid from the tracings 1 in $(2.5 \mathrm{~cm})$ above midspan $(C L+2.5 \mathrm{~cm})$. The solid line represents perfect agreement of the two freezing fractions and the shaded band indicates the limits for $\pm 10 \%$ agreement. A linear fit to the data is shown as a dashed line.

The linear fit to the data fell within the $\pm 10 \%$ agreement band, although on average $n_{e}$ values tended to be about $5 \%$ lower than the $n_{a}$. The value of $n_{e}$ found from equation (10) is inversely proportional to the value of $L W C$ through the accumulation parameter (eq. (11)). Because the uncertainties for the $L W C$ and $A_{c}$ were both estimated to be about $\pm 10 \%$, this agreement is quite good.

Bilanin ${ }^{23}$ performed a similar study using a limited set of ice-shape data from Ruff. Bilanin found agreement of $n_{e}$ and $n_{a}$ at rime, but the two deviated significantly for the lowest freezing fractions. He concluded that the Messinger analysis for freezing fraction had serious deficiencies, probably because surface-water effects, particularly splashing, were not included in the heat balance. However, Bilanin did not consider the possibility that the facility $L W C$ calibration or the uncertainty in the leadingedge thickness for low freezing fractions might have affected his results.

Unlike Bilanin's results, the experimentally-determined freezing fractions for the Anderson and Tsao study in figure 6 showed no systematic deviation from the analytical values at low freezing fractions. This consistently good agreement between $n_{e}$ and $n_{a}$ over a range of conditions including both fully rime and fairly warm glaze argued against the contention that the Messinger freez-

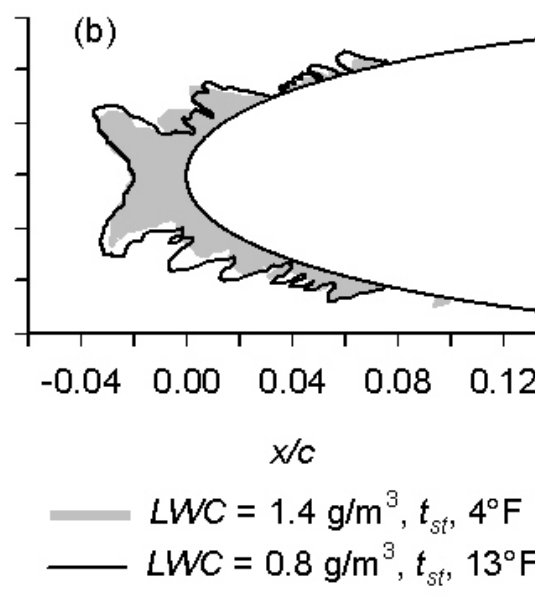

(b) Constant Freezing Fraction. $n_{0}=0.52$.

(a) Constant Static Temperature. $t_{s t}=11^{\circ} \mathrm{F}\left(-12^{\circ} \mathrm{C}\right)$

Figure 5. Effect of $L W C$ on Ice Shape. ${ }^{20}$ NACA 0012 Airfoil; $c$, 21 in $(53.3 \mathrm{~cm})$; $V, 150 \mathrm{mph}(67 \mathrm{~m} / \mathrm{s}) ; \delta, 30 \mu \mathrm{m} ; \tau, 5.2-7.3 \mathrm{~min} ; \beta_{0}, 0.80 ; A_{c}, 1.90$. 


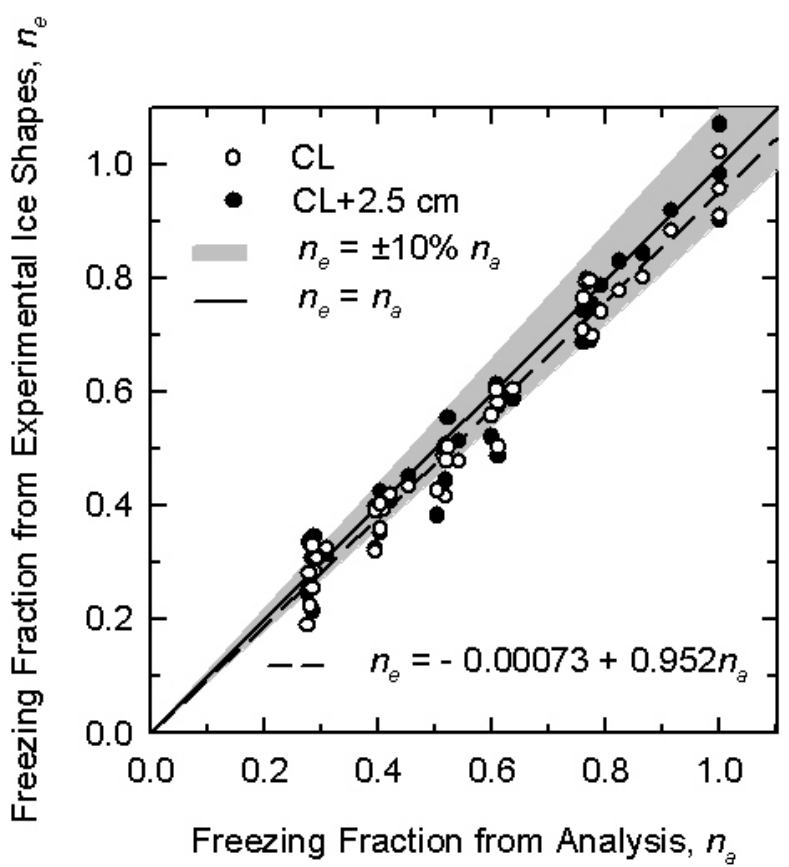

Figure 6. Experimental and Analytical Freezing Fractions of Anderson and Tsao. ${ }^{22}$

ing fraction formulation neglects any important surfacewater effects. On the contrary, for Appendix C icing conditions, the experimental results appeared to validate the Messinger freezing fraction formulation expressed in equation (28).

Besides the consistency between $n_{e}$ and $n_{a}$ over the range of freezing fractions evaluated, Anderson and Tsao showed that when conditions were such that equation (28) gave $n_{a}=1$, ice shapes as well as the white appearance of ice were typical of fully rime ice. The rime shape in figure 7 is shown with a shaded cross section. A second shape, produced at a temperature giving an analytical freezing fraction of 0.91 , is represented with a solid line. This shape differed from the rime in that a narrow strip of ice at the leading edge changed from the characteristic white appearance of rime to a slightly transparent form. At the same time the smooth, convex shape of rime was replaced at the leading edge with a slight valley. The remainder of the ice aft of this narrow strip maintained the rime appearance.

Thus, the use of the Messinger analysis leads to a calculated freezing fraction of 1 when ice shapes are indeed fully rime and less than 1 when glaze features begin to show at the leading edge. These results again show the strong consistency between the Messinger freezing fraction of equation (28) and experimental ice shapes.

Anderson and Tsao also looked at the effects of calculating the freezing fraction with 2 minor modifications. The first was to use the model chord instead of twice the leading-edge radius, and the second substituted the average Nu around a cylinder ${ }^{14}$

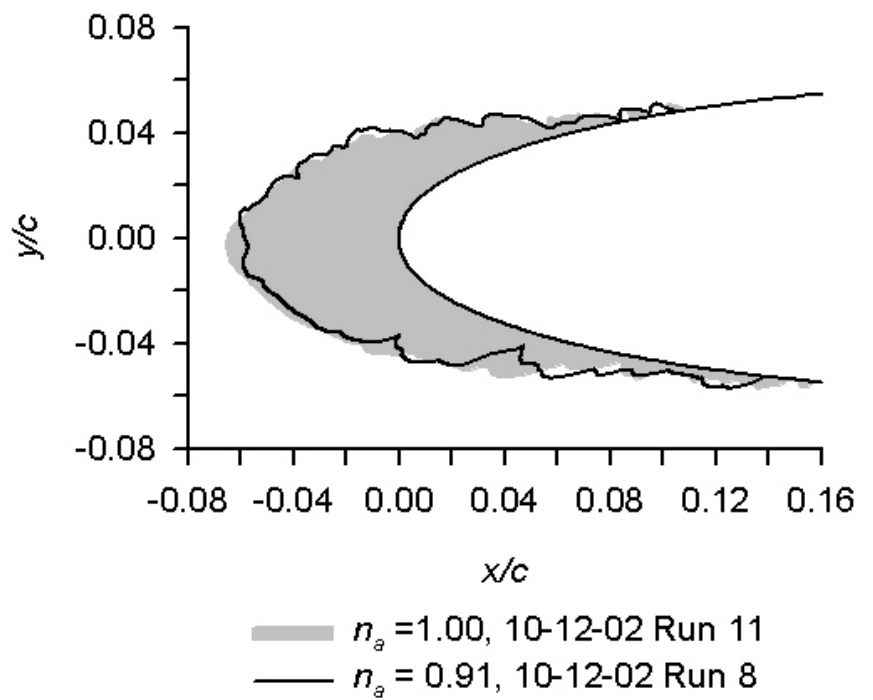

Figure 7. Effect of Freezing Fraction on Ice Shape at $n_{0}$ near 1. NACA 0012 Airfoil; $c, 21$ in $(53.3 \mathrm{~cm}) ; V, 115$ $\mathrm{mph}(51 \mathrm{~m} / \mathrm{s}) ; \delta, 40 \mu \mathrm{m} ; L W C, 1.14 \mathrm{~g} / \mathrm{m}^{3} ; t_{s t},-13$ and $-7^{\circ} \mathrm{F}$ (-25. and $\left.-22^{\circ} \mathrm{C}\right) ; \beta_{0}, 0.84 ; A_{c}, 2.43 ; b, 0.57 ; \phi, 40-44^{\circ} \mathrm{F}$ $\left(21-25^{\circ} \mathrm{C}\right) ; \theta, 52-59^{\circ} \mathrm{F}\left(29-33^{\circ} \mathrm{C}\right)$.

$$
N u=0.0239 R e^{0.805}
$$

for the stagnation value of equation (14). Both of these changes led to somewhat poorer agreement between the values of $n_{e}$ and $n_{a}$, but more significantly gave analytical freezing fractions of 0.82 to 0.89 for the icing tests that produced the fully rime ice shown in figure 7 .

These comparisons illustrate how it is possible to apply simple checks of experimental consistency to expose problems with particular analytical methods for calculating freezing fraction. At the same time, because fully rime is easy to recognize, equation (10) provides a simple way to validate facility $L W C$ calibrations. For this purpose, tests should be made at temperatures cold enough to result in fully rime ice. With $\beta_{0}$ determined from equation (8) and the stagnation ice thickness measured from the experimental accretion, equation (10) can be solved for the actual $A_{c}$, and the true $L W C$ found from equation (11).

\section{SIMILARITY OF SURFACE-WATER DYNAMICS}

Scaling methods developed from the 1950's through the 1970's relied on matching scale and reference values of some or all of the parameters $K_{0}$, (or $\beta_{0}$ ) $A_{c}$, and $n_{0}$. Given a set of reference conditions and choosing scale model size, Ruff used these parameters plus $\phi$ and $\theta$ from equations (26) and (27) to provide five equations to solve for scale temperature, pressure, drop MVD, cloud $L W C$ and spray duration. All of these earlier methods, including Ruff's, left the arbitrary choice of scale velocity to the user. In this section, it will be shown that velocity has an effect on ice shape independent of its effect on the similarity parameters identified so far. This effect of 
velocity appears to be associated with surface-water phenomena, as will be seen below.

In 1988 Bilanin $^{23}$ presented a Buckingham- $\pi$ analysis in which he concluded that surface-water phenomena had to be included in icing scaling methods. Olsen and Walker $^{24}$ and Hansman, et al, ${ }^{25,26,27}$ studied surface effects and surface water during ice accretion, presenting additional evidence that these were important phenomena to consider in ice accretion. From close-up photographic studies, it was observed that for glaze ice accretion unfrozen water on the ice surface tended to coalesce to form beads. These beads sometimes were swept downstream and sometimes froze in place. Bi$\operatorname{lanin}^{23,28}$ also argued that drop splashing on impact might affect the shape of the ice accreted.

Hansman and Turnock ${ }^{26}$ found that when a surfactant was added to the icing spray water, the ice appearance and shape changed significantly, with the glaze horns moving toward the leading edge. Similar observations were made by Bilanin and Anderson. Figure 8 includes published ${ }^{28}$ and unpublished data from their studies and compares ice shapes with and without surfactant addition to the spray for velocities of 105, 150 and $209 \mathrm{mph}$. The shaded ice shapes were obtained with the NASA Glenn IRT de-mineralized water supply with no surfac- tant added, and the shape represented by the solid line resulted from surfactant addition to the water. Other than the addition of surfactant the same test conditions were used for each pair of tests, as shown in the accompanying table. Surfactant addition reduced the surface tension to roughly half that of water. Because $\beta_{0}$, $A_{c}$ and $n_{0}$ were the same for each pair of tests, the leading-edge ice thickness was also nearly the same. However the included angle between the horns decreased dramatically when surfactant was added. Horn angle also decreased when velocity increased although the freezing fraction was approximately the same for all tests. Thus, both surface tension and velocity have an effect on ice shape independent of freezing fraction, and scale velocity cannot be chosen arbitrarily. Clearly, then, a similarity parameter dependent on the ratio $V$ ${ }^{e 1} / \sigma_{w a}{ }^{e 2}$ must be included in scaling methodology, where the powers $e 1$ and $e 2$ still need to be determined.

Kind, et $\mathrm{al}^{29,30}$ considered the capillary number, $\mu_{w} V / \sigma_{\text {wa }}$, to describe the phenomena related to the surface water on glaze ice accretions. The capillary number is the ratio of viscous forces to surface-tension forces. When scale tests use water with viscosity and surface tension that match the reference values, matching of the capillary number is equivalent to matching the

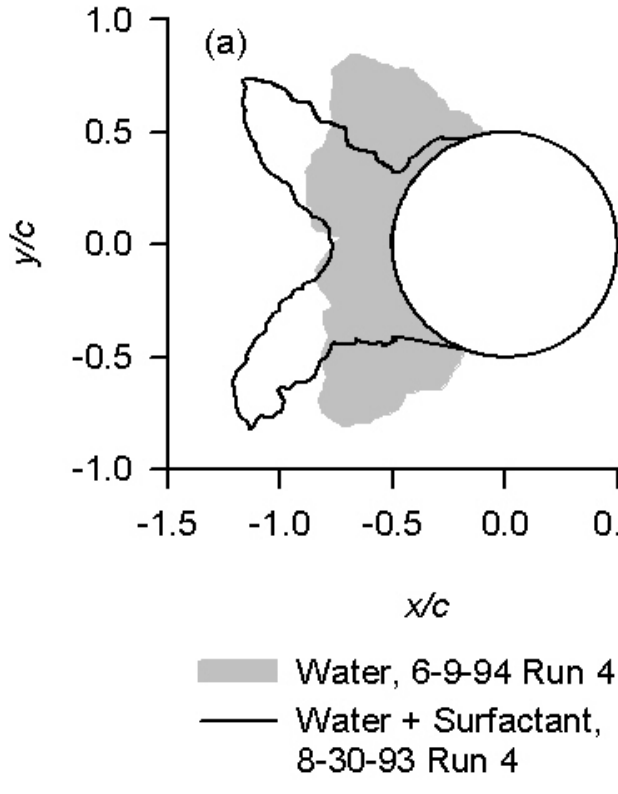

(a) $V=105 \mathrm{mph}(47 \mathrm{~m} / \mathrm{s})$

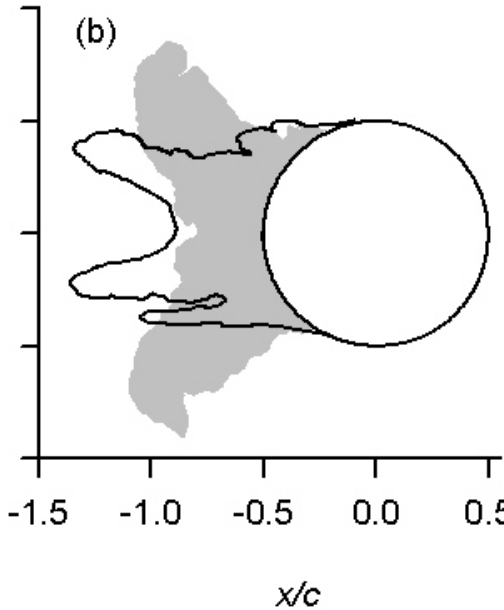

Water, 8-27-93 Run 9

Water + Surfactant, 8-30-93 Run 5 (b) $V=150 \mathrm{mph}(67 \mathrm{~m} / \mathrm{s})$

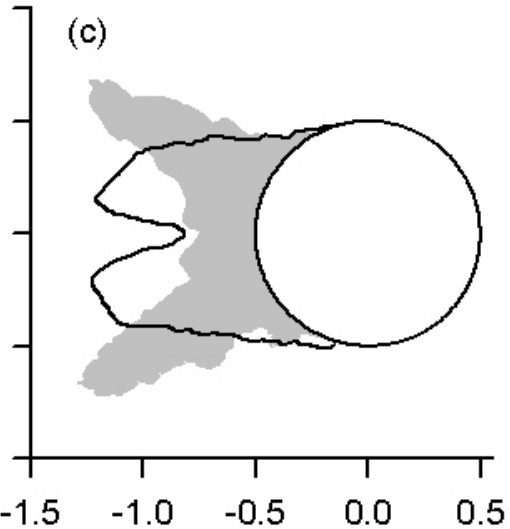

$x / c$

\begin{tabular}{|c|c|c|c|c|c|c|c|c|c|c|c|c|c|c|c|}
\hline ate/Run & $\begin{array}{l}d, \\
\text { in }\end{array}$ & $\begin{array}{l}t_{s t}, \\
{ }^{\circ} \mathrm{F}\end{array}$ & $\begin{array}{c}V, \\
\mathrm{mph}\end{array}$ & $\begin{array}{c}\delta, \\
\mu \mathrm{m}\end{array}$ & $\begin{array}{l}\angle W C, \\
\mathrm{~g} / \mathrm{m}^{3}\end{array}$ & $\begin{array}{c}\tau, \\
\min \end{array}$ & $\begin{array}{c}\sigma_{\text {wa }} \\
\text { dyne/ } \\
\mathrm{cm}\end{array}$ & $\begin{array}{l}\beta_{0} \\
\%\end{array}$ & $A_{c}$ & $n_{0}$ & $b$ & $\begin{array}{l}\phi, \\
{ }^{\circ} \mathrm{F}\end{array}$ & $\begin{array}{l}\theta, \\
{ }^{\circ} \mathrm{F}\end{array}$ & $\begin{array}{l}R e \\
10^{4}\end{array}$ & $\begin{array}{c}W e_{L} \\
10^{6}\end{array}$ \\
\hline $6-9-94 / 4$ & 2 & 18 & 105 & 40.0 & 1.16 & 16.0 & 65 & 66.0 & 1.13 & 0.28 & & 13.7 & 20.3 & 18.5 & 1.73 \\
\hline $8-30-$ & 2 & 18 & 105 & 40.0 & 1.17 & 16.0 & 30 & 66.0 & & 0.29 & 0.76 & 13.9 & 20.7 & 18.5 & 3.71 \\
\hline 8-2 & 2 & 11 & 150 & & 1.3 & & 65 & & 1. & & & & & & \\
\hline $8-30-93 / 5$ & 2 & 11 & 150 & 34.1 & 1.39 & 10.2 & 30 & 65.5 & 1.23 & 0.32 & 1.08 & 20.3 & 28.1 & 26.8 & \\
\hline $8-2$ & 2 & 10 & 209 & 30.0 & 1.10 & & 65 & 65.6 & 1.20 & 031 & 1.03 & 20.2 & 25.2 & 36.6 & \\
\hline $8-30-93 / 3$ & 2 & 10 & 209 & 30.0 & 1.10 & 9.2 & 30 & 65.6 & 1.22 & 0.31 & 1.03 & 19.6 & 24.7 & 36.4 & 8 \\
\hline
\end{tabular}

Figure 8. Effect of Surfactant and Velocity on Ice Shape. Vertical Cylinders Tested in the NASA Glenn IRT. Published ${ }^{28}$ and Unpublished Ice-Shape Data from Tests by Bilanin and Anderson. 
scale and reference velocity. However, studies of the effect of scale velocity ${ }^{31,32}$ showed that for subscale models the scale velocity must be higher than the reference. Therefore it is unlikely that the capillary number will prove to be an important similarity parameter by itself.

Chen's ${ }^{11}$ results discussed above (see fig. 3), and others like them for NACA 0012 airfoils, show that drop size and collection efficiency appear to have little effect on the main ice shape. Therefore, the parameter being sought cannot be dependent on $\delta$. Chen also evaluated the effect of model size, and figure 9 shows that with $\beta_{0}, A_{c}, n_{0}, b, \phi$ and $\theta$ constant a reduction in chord from 36 to 12 in moved the glaze horns rearward. This is the same effect shown in figure 8 for decreasing velocity.

The previous section showed that the temperature and $L W C$ do not have effects on the ice shape independent of the freezing fraction. Thus, the supplementary parameter does not need to include these test conditions, and its general form must be

$$
P=\text { constant } \frac{V^{e 1} c^{e 2}}{\sigma_{w a}^{e 3}}
$$

This form suggests a Weber number based on chord:

$$
W e_{c}=\frac{V^{2} c \rho_{a}}{\sigma_{w a}}
$$

Studies by Bartlett ${ }^{33,}{ }^{34}$ and Oleskiw, et. al. ${ }^{35}$ found no measurable effect of pressure on ice shape. These observations rule out the dependence on air density in equation (31), making water density a more likely choice. Furthermore, the length may not be chord itself but rather some physical characteristic related to the accreting ice that is proportional to chord; for example, the water-film thickness. Because this length is not yet identified, $L$ will be used to represent it, as follows

$$
W e_{L}=\frac{V^{2} L \rho_{w}}{\sigma_{w a}}
$$

The results of figure 9 suggest that $L \propto c$, or, since the leading-edge radius is proportional to chord, $L \propto d$. Then, from equation (32) the scale velocity found from matching $W e_{L, S}$ to $W e_{L, R}$ is

$$
V_{S}=V_{R} \sqrt{\frac{d_{R}}{d_{S}}}
$$

Some preliminary scaling results with $W e_{L}$ matched were reported by Anderson and Tsao. ${ }^{36}$ An example is shown in figure 10 for scaling from 36- to 21 -in chord for NACA 0012 airfoils. Note that the stagnation collection efficiencies for the two tests do not match, so the conditions do not strictly satisfy usual scaling requirements. However, it was shown in figure 3 that $\beta_{0}$ does not have a strong effect on the main ice shape. More important than $\beta_{0}$ matching is that the product $\beta_{0} A_{c}$ was nearly the same for the tests shown. The shapes of figure 10 as well as others in reference 36 for the same scale ratio at freezing fractions of 0.3 and 0.4 showed good agreement between scale and reference. To date there have been no results published for greater scale ratios for which the $W e_{L}$ was matched, and such data are needed for more confidence in this approach.

Although the conditions for the tests of figure 10 left the $\phi$ mismatched, the good agreement of the ice shapes suggests again that $\phi$ may not be as important a similarity parameter as once believed. Note also that the temperatures for the two tests were significantly different; this result gives further evidence that static temperature does not need to be matched for good scaling. 


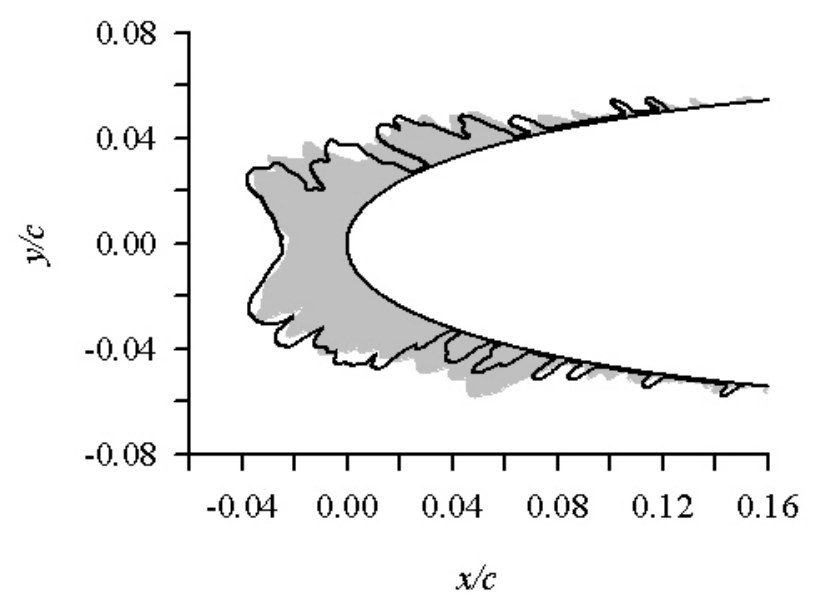

c, 36 in; 2-8-02 Run 7

-, $21 \mathrm{in;} 11-13-00$ Run 5

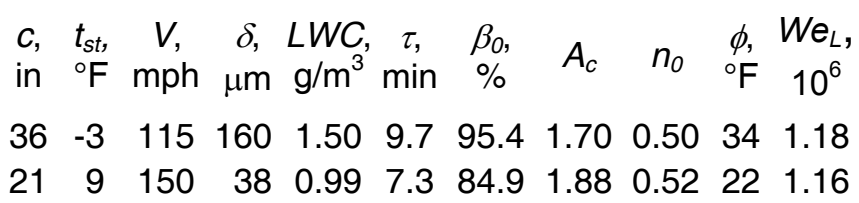

Figure 10. Scaling Using $W e_{L, S}=W e_{L, R}$ to Determine Scale Velocity. ${ }^{36}$ NACA 0012 Airfoils.

There are a variety of Weber numbers based on other lengths and different velocities which have been matched to find scale velocity. One such parameter, for example, ${ }^{30,31,32}$ was based on drop size and water properties,

$$
W e=\frac{V^{2} \delta \rho_{w}}{\sigma_{w a}}
$$

A form of equation (32) in which $h_{\text {film }}$, the water-film thickness, was substituted for $L$ was evaluated by Anderson and Feo. ${ }^{37}$ Nearly the same Weber number was proposed and evaluated by Kind and colleagues, ${ }^{18,19,38,39}$ but with $\rho_{a}$ used in place of $\rho_{w}$. A Weber number based on the velocity of the water film instead of the free stream could also be considered.

In addition to these Weber numbers, $\mathrm{Feo}^{40}$ suggested that the water film thickness might itself be a critical dimension controlling surface water dynamics. From studies of sprays impinging on a cylindrical probe at abovefreezing temperatures he found that water-film thickness was proportional to the product $L W C^{1 / 2} R e^{-1 / 4}$.

A scale velocity obtained as the average of that found from matching We (eq. (34)) and that matching $R e$ (eq. (1)) has also been considered. ${ }^{31,32}$ For half-size scaling, the average velocity method gives a scale velocity that is only about $20 \%$ higher than the one found by matching $W e_{L}$. The use of other Weber numbers or of the waterfilm thickness nearly all give scale velocities within $\pm 20 \%$ of that found from matching $W e_{L}$, even for scale sizes as small as $1 / 4$ the reference. Choosing the best among the different parameters by comparing scale to reference shapes is not productive because ice shapes are not sensitive enough to velocity to be able to discriminate between these differences. Therefore, until additional research is done, it is not possible to positively identify the similarity parameter, or parameters, that best represents surface physics, and finding scale velocity by using equation (33) appears to be a satisfactory approach at the present time.

\section{OTHER PHENOMENA}

The physical models for icing on which the similitude parameters have been based have not been fully verified and probably do not include all phenomena that may have some effect on the ice accretion process. Closeup studies of water impact and freezing on surfaces were made by Olsen and Walker. ${ }^{24}$ They believed that shedding of water from the surface, particularly from the tips of the horns, is a significant part of the ice-accretion process. Whether this water is subsequently reentrained and deposited aft of the main ice shape is not known. In addition to water shedding, ice shedding is a major consideration for situations involving high speeds, rotorcraft and deicing systems. Olsen and Newton ${ }^{8}$ and Ruff $^{6}$ have discussed the similitude requirements for shedding.

Both of these shedding phenomena take place away from stagnation, which is where the scaling analyses are focused. Thus, the present approach to scaling cannot easily incorporate them. However, for some conditions these events might need to be considered for accurate simulation of horn shape. Until high-speed, close-up studies can better identify the processes taking place, shedding can not be analyzed. Fortunately, for typical Appendix $\mathrm{C}$ conditions, reasonable success with scaling has been demonstrated without including a shedding analysis.

\section{CONCLUSION}

This paper reviewed the similarity parameters identified by various research studies from the standpoint of icing scaling. Scaling methods incorporate the physics of icing by requiring that scale and reference values of the most important similarity parameters should match.

From the drop momentum equation, Langmuir and Blodgett ${ }^{7}$ derived the modified inertia parameter, $K_{0}$, given by equation (3). The stagnation collection efficiency at the leading edge, $\beta_{0}$, is directly related to $K_{0}$ by equation (8). Main ice shapes are not particularly sensitive to $\beta_{0}$, so some flexibility in matching this parameter appears to be possible. By matching scale and reference values of $K_{0}$ or $\beta_{0}$ the scale drop size can be determined.

From an analysis of the water catch the accumulation parameter can be formulated, and from it the scale icing time can be determined (equation (12)). 
Messinger's ${ }^{12}$ freezing fraction, $n_{0}$, of equation (28) was derived from the surface energy balance. $n_{0}$ has a strong effect on the glaze ice horn angle and the leading-edge thickness. A second parameter from the energy balance is $\phi$, the water-energy transfer parameter, given by equation (26). The Ruff scaling method ${ }^{6}$ matches $\phi_{S}$ to $\phi_{R}$ to find scale temperature and $n_{0, S}$ to $n_{0, R}$ to find scale $L W C$. However, ice shapes appear to be much less sensitive to $\phi$ than to $n_{0}$. The expression for freezing fraction presented in this paper was validated by comparing analytical and experimental values. The appearance of experimental ice shapes was also consistent with the analytical values of freezing fraction: when the freezing fraction was unity, ice shapes had the typical look of rime ice, and when $n_{0}$ was less than unity, glaze features appeared at the leading edge.

Consideration of surface-water dynamics led to the conclusion that an additional similarity parameter is needed to find scale velocity. A Weber number based on freestream velocity and model size (eq. (32)) was presented, but there are other possible Weber numbers as well as parameters such as the non-dimensional water-film thickness that could be used. Because there is not a significant difference between the values of velocity found using most of the proposed parameters, it is not possible to discriminate between them by evaluating scaling results. Additional studies of surface phenomena, including water-film behavior and drop impact and splashing, are needed to understand the physics better.

\section{REFERENCES}

1 von Glahn, Uwe H., "Use of Truncated Flapped Airfoils for Impingement and Icing Tests of Full-Scale Leading-Edge Sections," NACA RM E56E11, July 1956.

2 Saeed, Farooq, Selig, Michael S. and Bragg, Michael B., "Design of Subscale Airfoils with Full-Scale Leading Edges for Ice Accretion Testing," AIAA-960635, January 1996 and J. Aircraft, vol. 34, no. 1, January-February 1997, pp 94-100.

3 Saeed, Farooq, Selig, Michael S. and Bragg, Michael B., "Experimental Validation of the Hybrid Airfoil Design Procedure for Full-Scale Ice Accretion Simulation," AIAA-98-0199, January 1998.

4 Bragg, M.B., Gregorek, G.M. and Shaw, R.J., "An Analytical Approach to Airfoil Icing," AIAA-81-0403, January 1981.

5 Bragg, Michael B., "A Similarity Analysis of the Droplet Trajectory Equation," AIAA J, vol. 20, no. 12, December 1982, pp 1681-1686.

6 Ruff, G.A., "Analysis and Verification of the Icing Scaling Equations," AEDC-TR-85-30, Vol 1 (Rev), March 1986.

7 Langmuir, Irving and Blodgett, Katharine B., "A Mathematical Investigation of Water Droplet Trajecto- ries," Army Air Forces Technical Report No. 5418, February 1946.

8 Olsen, William and Newton, James, "Experimental and Analytical Evaluation of Existing Icing Scaling Laws," unpublished draft of NASA Technical Memorandum, 1986.

9 Charpin, Francois and Fasso, Guy, "Icing Testing in the Large Modane Wind Tunnel on Full Scale and Reduced Scale Models," L'Aeronautique et l'Astronautique, no 38, 1972. English translation published as NASA TM-75373.

10 Wright, W.B., "Users Manual for the Improved NASA Lewis Ice Accretion Code, LEWICE 1.6," NASA CR 198355, June 1995.

11 Chen, Shu-Cheng, unpublished GLC 305 icing studies in NASA Glenn IRT, March, April, September and October 1998.

12 Messinger, B.L., "Equilibrium Temperature of an Unheated Icing Surface as a Function of Airspeed," $J$. Aeron. Sci. vol. 20 no. 1, January 1953, pp 29-42.

13 Tribus, Myron; Young, G.B.W.; and Boelter, L.M.K., "Analysis of Heat Transfer Over a Small Cylinder in Icing Conditions on Mount Washington," Trans ASME vol 70, 1948, pp 971-976.

14 Kreith, Frank, Principles of Heat Transfer, International Textbook Co., Scranton, 1958.

15 Poinsatte, Philip E., "Heat Transfer Measurements from a NACA 0012 Airfoil in Flight and in the NASA Lewis Icing Research Tunnel," NASA CR 4278, March 1990.

16 Van Fossen, G.J.; Simoneau, R.J.; Olsen, W.A.; and Shaw, R.J., "Heat Transfer Distributions Around Nominal Ice Accretion Shapes Formed on a Cylinder in the NASA Lewis Icing Research Tunnel," AIAA-84-0017 and NASA TM-83557, January 1984.

17 Pruppacher, Hans R. and Klett, James D., Microphysics of Clouds and Precipitation, Reidel, Boston, 1980.

18 Kind, Richard J. and Oleskiw, Myron M., "Experimental Assessment of a Water-Film-Thickness Weber Number for Scaling of Glaze Icing," AIAA-20010836, January 2001.

19 Oleskiw, Myron M., Kind, Richard J. and McCullough, Telamon, "Further Assessment of a Proposed Additional Scaling Parameter and of Non-Matching Freestream Temperature for Glaze Icing Tests," AIAA2002-0520, January 2002.

20 Anderson, David N., "Methods for Scaling Icing Test Conditions," AIAA-95-0540 and NASA TM 106827, January 1995.

21 Anderson, David N., "Further Evaluation of Traditional Icing Scaling Methods," AIAA-96-0633 and NASA TM 104140, January 1996. 
22 Anderson, David N. and Tsao, Jen-Ching, "Evaluation and Validation of the Messinger Freezing Fraction," AIAA-2003-1218, January 2003.

23 Bilanin, A. J., "Proposed Modifications to the Ice Accretion/lcing Scaling Theory," AIAA-88-0203, January 1988.

24 Olsen, W. and Walker, E., "Experimental Evidence for Modifying the Current Physical Model for Ice Accretion on Aircraft Surfaces," NASA TM 87184, 1986.

25 Hansman, R. John, Jr. and Turnock, Stephen R., "Investigation of Microphysical Factors which Influence Surface Roughness During Glaze Ice Accretion," $4^{\text {th }}$ International Workshop on Atmospheric Icing of Structures, Paris, September 1988.

26 Hansman, R. John, Jr. and Turnock, Stephen R., "Investigation of Surface Water Behavior During Glaze Ice Accretion," J. Aircraft, vol. 26 no. 2, February 1989, pp 140-147.

27 Hansman, R.J., Breuer, K.S., Hazan, D., Reehorst, A. and Vargas, M., "Close-up Analysis of Aircraft Ice Accretion," AIAA-93-0029, January 1993.

28 Bilanin, Alan J. and Anderson, David N., "Ice Accretion with Varying Surface Tension," AIAA-95-0538 and NASA TM 106826, January 1995.

29 Kind, R.J., "A Critical Assessment of the Similarity Requirements for Sub-Scale Simulation of Ice Accretion on Aircraft," section 4.1 in Ice Accretion Simulation, final report of AGARD/FDP Working Group 20, AGARD Report AR-344, in press, October 1997.

30 Kind, R.J., Dillon, T., Gaydos, J.A. and Oleskiw, M., "Evidence for the Importance of Scaling Viscous Effects in the Water Film in Glaze Icing Tests," AIAA-980196, January 1998.
31 Anderson, David N. and Ruff, Gary A., "Evaluation of Methods to Select Scale Velocities in Icing Scaling Tests," AIAA-99-0244, January 1999.

32 Anderson, David N., "Effect of Velocity in Icing Scaling Tests," AIAA-2000-0236, January 2000.

33 Bartlett, C. Scott, "An Analytical Study of Icing Similitude for Aircraft Engine Testing," DOT/FAA/CT86/35 and AEDC-TR-86-26, October 1986.

34 Bartlett, C. Scott, "Icing Scaling Considerations for Aircraft Engine Testing," AIAA-88-0202, January 1988.

35 Oleskiw, Myron M., De Gregorio, Fabrizio and Esposito, Biagio, "The Effect of Altitude on Icing Tunnel Airfoil Icing Simulation," Proceedings of the FAA International Conference on Aircraft Inflight lcing, DOT/FAA/AR-96/81,II, August 1996, pp 511-520.

36 Anderson, David N. and Tsao, Jen-Ching., "Additional Results of Ice-Accretion Scaling at SLD Conditions," AIAA-2003-0390, January 2003.

37 Anderson, David N. and Feo, Alejandro, "IceAccretion Scaling Using water-Film Thickness Parameters," AIAA-2002-0522, January 2002.

38 Kind, Richard J., "Assessment of Importance of Water-Film Parameters for Scaling of Glaze Icing," AIAA-2001-0835, January 2001.

39 Kind, R.J., "Scaling of Icing Tests - A Review of Recent Progress," AIAA-2003-1216, January 2003.

40 Feo, A., "Icing Scaling with Surface Film Thickness Similarity for High LWC Conditions," AE/PRO/4420/184/INTA/00, October 2000. 


\section{NOMENCLATURE}

$A_{c} \quad$ accumulation parameter, dimensionless

AOA angle of attack, ${ }^{\circ}$

$b \quad$ relative heat factor, dimensionless

c airfoil chord, in

$c_{p} \quad$ constant-pressure specific heat, Btu/lbm R

$C_{D} \quad$ drag coefficient of drop, dimensionless

$d \quad$ cylinder diameter or twice the airfoil leadingedge radius, in

$D_{v} \quad$ diffusivity of water vapor in air, $\mathrm{ft}^{2} / \mathrm{s}$

e 1, e 2, e 3 powers in equation (30), dimensionless

$h_{c} \quad$ convective heat transfer coefficient, Btu/hr $\mathrm{ft}^{2} \mathrm{R}$

$h_{\text {film }} \quad$ water-film thickness, in

$h_{G} \quad$ gas-phase mass transfer coefficient, lbm/hr ft ${ }^{2}$

$k$ thermal conductivity, Btu/hr ft R

$K \quad$ drop inertia parameter, dimensionless

$K_{0} \quad$ modified inertia parameter, dimensionless

$L \quad$ undefined length proportional to model diameter or chord, in

LWC liquid water content of cloud, $\mathrm{lbm} / \mathrm{ft}^{3}$

$\dot{m} \quad$ mass flux of water per unit time, $\mathrm{lbm} / \mathrm{ft}^{2} \mathrm{~s}$

$\dot{m}_{e} \quad$ mass flux of water evaporated, $\mathrm{lbm} / \mathrm{ft}^{2} \mathrm{~s}$

$M \quad$ Mach number, dimensionless

$n \quad$ freezing fraction, dimensionless

$n_{a} \quad$ analytical value of freezing fraction, dimensionless

$n_{e} \quad$ freezing fraction found from leading-edge thickness of experimental ice shapes, dimensionless

$\mathrm{Nu} \quad$ Nusselt number, dimensionless

$p \quad$ pressure, psi

$p_{w w} \quad$ vapor pressure of water over liquid water, psia

$p_{w} \quad$ vapor pressure of water in the atmosphere, psia

$\mathrm{Pr} \quad$ Prandtl number of air, dimensionless

$q_{c} \quad$ surface heat loss due to convection, Btu/hr $\mathrm{ft}^{2}$

$q_{e} \quad$ surface heat loss from evaporation, Btu/hr $\mathrm{ft}^{2}$

$q_{f} \quad$ surface heat gain from release of latent heat of fusion, Btu/hr $\mathrm{ft}^{2}$

$q_{k} \quad$ surface heat gain from kinetic energy of water drops, Btu/hr $\mathrm{ft}^{2}$

$q_{w} \quad$ surface heat loss to raise temperature of impinging water to freezing, Btu/hr $\mathrm{ft}^{2}$

$r$ recovery factor, dimensionless

$r_{l e} \quad$ leading-edge radius, in

$r_{A}$ evaporative-to-convective heat transfer term, dimensionless

$R_{a} \quad$ gas constant for air, lbf ft/lbm R

$R e \quad$ Reynolds number, dimensionless

$R e_{\text {rel }}$ Reynolds number of drop relative to airstream, dimensionless
$R e_{\delta} \quad$ Reynolds number of drop, dimensionless

$s \quad$ Surface distance from airfoil stagnation, in

Sc Schmidt number of air, dimensionless

$t$ temperature, ${ }^{\circ} \mathrm{F}$

$t_{b l} \quad$ temperature of air in boundary layer, ${ }^{\circ} \mathrm{F}$

$t_{f} \quad$ freezing temperature of water, $0^{\circ} \mathrm{F}$

$t_{\text {film }} \quad$ film temperature, ${ }^{\circ} \mathrm{F}$

$T$ absolute temperature, $\mathrm{R}$

$T_{f} \quad$ absolute freezing temperature of water, $\mathrm{R}$

$u \quad$ air velocity vector, dimensionless

$V \quad$ free-stream velocity (air speed), $\mathrm{mph}$

We Weber number based on drop diameter, dimensionless

$W e_{c} \quad$ Weber number based on model length dimension, dimensionless

$W e_{L} \quad$ Weber number based on length $L$, dimensionless

$x \quad$ horizontal coordinate, in

$y \quad$ vertical coordinate, in

$\beta \quad$ catch efficiency, dimensionless

$\gamma \quad$ ratio of specific heats for air, 1.4

$\delta \quad$ drop median volume diameter (MVD), $\mu \mathrm{m}$

$\Delta \quad$ ice thickness, in

$\theta \quad$ air energy transfer parameter, $\mathrm{R}$

$\lambda$ drop range in absence of gravity, $\mathrm{ft}$

$\lambda_{\text {Stokes }}$ drop range in absence of gravity if Stokes' law applies, $\mathrm{ft}$

$\Lambda_{f} \quad$ latent heat of freezing, Btu/lbm

$\Lambda_{v} \quad$ latent heat of vaporization, Btu/lbm

$\mu \quad$ viscosity, $\mathrm{lbm} / \mathrm{ft} \mathrm{s}$

$\rho \quad$ density, $\mathrm{Ibm} / \mathrm{ft}^{3}$

$\sigma_{w a} \quad$ Surface tension of water over air, lbf/ $/ \mathrm{tt}$

$\tau \quad$ icing time, $\min$

$\phi \quad$ drop energy transfer parameter, $\mathrm{R}$

General Subscripts:

0 stagnation value

a air

$i \quad$ ice

$R \quad$ reference conditions

$s \quad$ surface

$S \quad$ scale conditions

st static

tot total

w water 


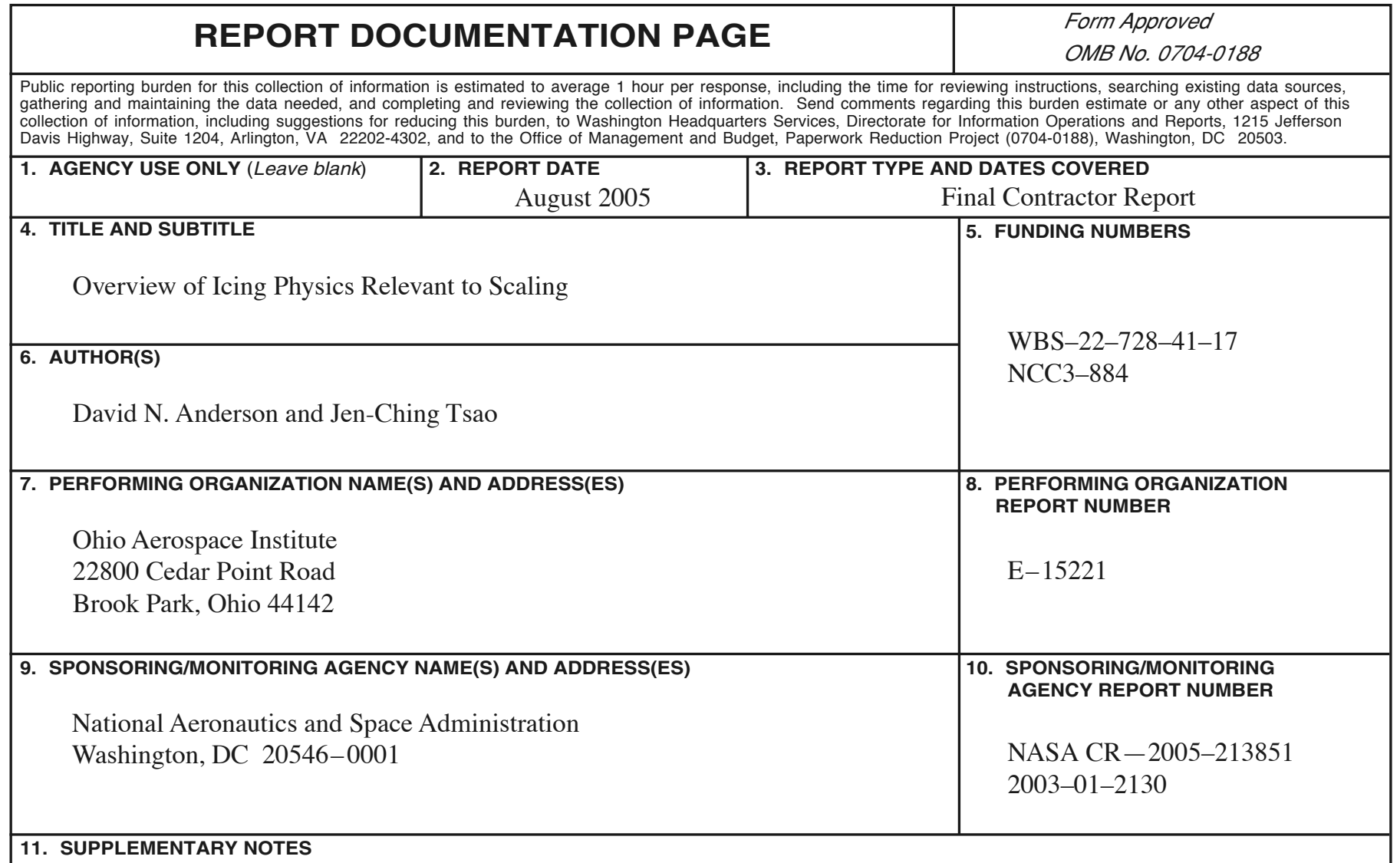

Prepared for the FAA In-Flight Icing/Ground De-Icing International Conference sponsored by the Society of Automotive Engineers, Chicago, Illinois, June 16-20, 2003. Project Manager, Thomas H. Bond, Instrumentation and Controls Division, NASA Glenn Research Center, organization code RI, 216-433-3900.

12a. DISTRIBUTION/AVAILABILITY STATEMENT

12b. DISTRIBUTION CODE

Unclassified - Unlimited

Subject Category: 03

Available electronically at http://gltrs.grc.nasa.gov

This publication is available from the NASA Center for AeroSpace Information, 301-621-0390.

13. ABSTRACT (Maximum 200 words)

An understanding of icing physics is required for the development of both scaling methods and ice-accretion prediction codes. This paper gives an overview of our present understanding of the important physical processes and the associated similarity parameters that determine the shape of Appendix $\mathrm{C}$ ice accretions. For many years it has been recognized that ice accretion processes depend on flow effects over the model, on droplet trajectories, on the rate of water collection and time of exposure, and, for glaze ice, on a heat balance. For scaling applications, equations describing these events have been based on analyses at the stagnation line of the model and have resulted in the identification of several non-dimensional similarity parameters. The parameters include the modified inertia parameter of the water drop, the accumulation parameter and the freezing fraction. Other parameters dealing with the leading edge heat balance have also been used for convenience. By equating scale expressions for these parameters to the values to be simulated a set of equations is produced which can be solved for the scale test conditions. Studies in the past few years have shown that at least one parameter in addition to those mentioned above is needed to describe surface-water effects, and some of the traditional parameters may not be as significant as once thought. Insight into the importance of each parameter, and the physical processes it represents, can be made by viewing whether ice shapes change, and the extent of the change, when each parameter is varied. Experimental evidence is presented to establish the importance of each of the traditionally used parameters and to identify the possible form of a new similarity parameter to be used for scaling.

\begin{tabular}{|l|l|}
\hline 14. SUBJECT TERMS & 15. NUMBER OF PAGES
\end{tabular}

Icing physics; Scaling

22

\begin{tabular}{|c|c|c|c|}
\hline $\begin{array}{c}\text { 17. SECURITY CLASSIFICATION } \\
\text { OF REPORT } \\
\text { Unclassified }\end{array}$ & $\begin{array}{c}\text { 18. SECURITY CLASSIFICATION } \\
\text { OF THIS PAGE } \\
\text { Unclassified }\end{array}$ & $\begin{array}{c}\text { 19. SECURITY CLASSIFICATION } \\
\text { OF ABSTRACT } \\
\text { Unclassified }\end{array}$ & 20. LIMITATION OF ABSTRACT \\
\hline
\end{tabular}

NSN 7540-01-280-5500

Standard Form 298 (Rev. 2-89)

Prescribed by ANSI Std. Z39-18 298-102 

